Bryn Mawr College

Scholarship, Research, and Creative Work at Bryn Mawr College

Graduate School of Social Work and Social

Graduate School of Social Work and Social

Research Faculty Research and Scholarship

Research

2011

\title{
Race and the Local Politics of Punishment in the New World of Welfare
}

Richard C. Fording

Joe Soss

Sanford F. Schram

Bryn Mawr College, sschram@brynmawr.edu

Let us know how access to this document benefits you.

Follow this and additional works at: http://repository.brynmawr.edu/gsswsr_pubs

Part of the Social Work Commons

\section{Custom Citation}

Fording, Richard C., Joe Soss, and Sanford F. Schram. "Race and the Local Politics of Punishment in the New World of Welfare." American Journal of Sociology 116 (2011): 1610-1657.

This paper is posted at Scholarship, Research, and Creative Work at Bryn Mawr College. http://repository.brynmawr.edu/gsswsr_pubs/16

For more information, please contact repository@brynmawr.edu. 


\title{
Race and the Local Politics of Punishment in the New World of Welfare ${ }^{1}$
}

\author{
Richard C. Fording \\ University of Kentucky \\ Joe Soss \\ University of Minnesota \\ Sanford F. Schram \\ Bryn Mawr College
}

To illuminate how race affects the usage of punitive tools in policy implementation settings, we analyze sanctions imposed for noncompliant client behavior under welfare reform. Drawing on a model of racial classification and policy choice, we test four hypotheses regarding client race, local context, and sanctioning. Based on longitudinal and cross-sectional multilevel analyses of individual-level administrative data, we find that race plays a significant role in shaping sanction implementation. Its effects, however, are highly contingent on client characteristics, local political contexts, and the degree to which state governments devolve policy control to local officials.

\section{INTRODUCTION}

Over the past few decades, poverty governance in the United States has been transformed by the convergence of two broad reform movements.

\footnotetext{
${ }^{1}$ We are grateful to Scott Allard, Maria Cancian, Raymond Duvall, Ken Hoover, Linda Houser, Dana Patton, Mark Peffley, Stephen Pimpare, Frances Fox Piven, Stephen Rathegab Smith, John Tambornino, Pamela Winston, and D. Stephen Voss for providing valuable comments on earlier drafts. This research has been supported by the University of Kentucky Center for Poverty Research (UKCPR); the Institute for Research on Poverty (IRP) at the University of Wisconsin; the Center on Ethnicities,
} 
The first, often referred to as "paternalist," has shifted governance to a stance that is more overt in directing and supervising the behaviors of the poor (Mead 1997). Using images of disorder and dysfunction as justifications, public authorities have asserted an obligation to "tell the poor what to do" (Mead 1998). Thus, programs for poor people have been recast to emphasize behavioral expectations, administrative monitoring, incentives for right behavior, and penalties for noncompliance (Mead 1997). Means-tested benefits of various stripes, from nutritional assistance to housing support, have been made conditional on compliant behavior.

The sharp turn toward paternalism has intersected with a second development: the reorganization of governance along "neoliberal" lines. In the 1970s and 1980s, neoliberal reformers initially adopted a laissez-faire stance, seeking to reduce the state's influence on markets through deregulation and curtailments of the welfare state (Harvey 2005). Over time, however, they shifted to a more ambitious agenda (Peck and Tickell 2002). Today, neoliberalism encompasses a wide range of efforts to organize social relations according to principles of market rationality (Brown 2003). Rather than shrinking the state, neoliberals have sought to restructure it and harness its capacities for market purposes. They have embraced governmental authority while working to redirect it—redesigning its operations to reflect market principles, making it more reliant on market actors, and using it in affirmative ways to construct markets and impose market discipline (Brown 2006).

The convergence of these two streams marks a significant moment in American political development. Welfare programs today are administered and implemented through a decentralized network of actors, organized by quasi-market relations, and charged with the task of bringing discipline to the lives of the poor. Surveillance and behavioral control are, of course, old themes in the history of poverty governance (Katz 1996). In this respect, the new system can be seen as continuous with the long history of efforts to regulate and modify poor people's behaviors (Piven and Cloward 1971; Abramovitz 1988). Yet, if the new system is less than the sharp break with the past that some observers imagine (e.g., Mead 1998), it is also more than a simple recycling of old ideas and tactics (e.g., Somers and Block 2005). The present era is distinguished not by the

Communities, and Social Policy at Bryn Mawr College; and the Annie E. Casey Foundation. We are grateful to representatives of the Florida Department of Children and Families and Workforce Florida, Inc., for the data used in this article, and to Adam Butz for valuable research assistance. The opinions and conclusions expressed herein are solely those of the authors and should not be construed as representing the opinions or policy of the UKCPR, the IRP, the state of Florida, or any agency of the federal government. Direct correspondence to Richard C. Fording, Department of Political Science, University of Kentucky, Lexington, Kentucky, 40506-0027. E-mail: rford@uky.edu 
severity of its agenda but by the ways that old and new elements operate together as a particular system for disciplining the poor. To understand it, one must ask how the echoes of past practice (surveillance, stigma, regulation, etc.) intersect with new historical developments that have (1) repositioned the state as a collaborator and contractor in performancedriven, decentralized governing networks (Kettl 2002), (2) restructured the relationship between welfare programs and labor markets (Krinsky 2007), (3) redesigned welfare agencies as market operations (Ridzi 2009), (4) pushed poverty governance toward a more carceral emphasis (Wacquant 2009), and (5) recast welfare programs as therapeutic regimes designed to turn "welfare dependents" into competent "worker-citizens" (Schram 2000; Korteweg 2003).

As logics of violation and punishment have become more central to public aid programs, criminal justice and welfare policies have converged to create a "double regulation of the poor" (Wacquant 2009). Like earlier eras of poverty governance, the recent disciplinary turn has reflected a complex interplay of race, class, and gender dynamics (Nelson 1990; Gordon 1994; Mettler 1998; Hays 2003). Indeed, the racialized system of discipline that targets the poor today can be understood as gendered in four senses. First, its institutions have been built, politically, around gender-specific cultural images of poor racial minorities: the lawless, violent male of the underclass ghetto (Wacquant 2009) and the lazy and licentious welfare queen (Hancock 2004). Second, the system operates through gender-segregated institutions, with women making up roughly $90 \%$ of adult welfare recipients and men making up roughly $90 \%$ of prisoners (Haney 2004). Third, the common direction of change in welfare and criminal operations has been toward a "masculinizing of the state" as a paternalist, behavior-enforcing custodian (Wacquant 2009, p. 15). The "nanny state" of welfare protections and prison rehabilitation programs has been supplanted by a "daddy state" emphasizing direction, supervision, and punitive modes of discipline (Starobin 1998). Fourth, historically masculine images of the worker-citizen have been elevated and universalized as a behavioral norm, while, at the same time, women in welfare programs have been stripped of rights as both citizens and workers (Korteweg 2003; Collins and Mayer 2010). For former welfare recipients and prisoners, the sine qua non of civic reinstatement is the same: formal employment and wage-based support of one's children.

As decentralized disciplinary systems have moved to the forefront of poverty governance, the study of administrative practice has taken on greater urgency (Mead 2004). Because public benefits are now more contingent on recipient behavior, local policy implementers have had to reorganize their operations around the tasks of identifying and penalizing rule violators. To understand discipline as an element of governance, then, 
social scientists must do more than explain why mass publics or political jurisdictions vary in the extent to which they embrace such punitive policy designs. We must investigate how punitive policy tools are actually put into practice and, in so doing, clarify the social, political, economic, and organizational forces that shape decisions to discipline. It is here, in the operation of administrative discretion, that the state's capacity to punish collides with the core question of distributive politics posed by Harold Lasswell (1936): "Who gets what, when, how?"

This article presents an analysis of discipline at the frontlines of welfare reform, focusing on how patterns of punishment are affected by the interplay of race and politics. In the United States, there is a long history of social-policy tools being applied to racial groups in unequal ways (Lieberman 1998; Katznelson 2005). Today, however, the age of Jim Crow is a distant memory, de jure discrimination is banned, and norms of racial equality are widely embraced (Mendelberg 2001). In this post-civil rights context, how and why does race matter for disciplinary action in local welfare offices? Under what conditions do client racial characteristics become significant influences on decisions to impose penalties?

Since the 1960s, welfare programs have been widely understood as "black" programs focused on poor, female-headed families in black communities. Earlier eras of poor relief in the United States were marked by the exclusion of racial minorities (Lieberman 1998) and by efforts to conceal the presence of people of color in welfare caseloads (Mittelstadt 2005). Such policy practices were particularly widespread in the South and were facilitated by decentralized administration of welfare programs targeted for the so-called undeserving poor (Trattner 1999). In the 1960s, however, a turbulent decade of racial politics intersected with welfare rights activism to produce both objective and symbolic changes in the relationship between race and welfare provision (Quadagno 1994). Welfare rights victories led to a centralization of administrative control and a significant reduction in the amount of discretion given to frontline workers, thus easing eligibility restrictions and weakening discriminatory practices. As a result, the black share of women in the welfare caseload began to increase (Piven and Cloward 1971). At the same time, media coverage of poverty shifted toward a disproportionate emphasis on images of the black poor, especially in stories that focused on behavioral pathologies (Gilens 1999). The public image of the "lazy and licentious welfare queen" took center stage in debates over public assistance (Hancock 2004). These developments were strengthened by the racialized rhetoric that opportunistic political elites deployed in using welfare dependence and underclass pathology as electoral wedge issues (Neubeck and Cazenave 2001).

As a result, numerous studies confirm that racial attitudes operate today as a key determinant of public preferences regarding social programs and 
systems of punishment (Peffley, Hurwitz, and Sniderman 1997; Gilens 1999; Dyck and Hussey 2008). Likewise, studies suggest that as responsibility for welfare provision has shifted back to state and local governments in the wake of welfare reform, punitive policy tools have been adopted in a pattern that tracks with the racial composition of state populations (Hero 1998; Soss et al. 2001; Jacobs and Carmichael 2002; Fording 2003; Fellowes and Rowe 2004). While such evidence testifies to the enduring power of race in American politics, this evidence has limited value for understanding if or how race matters when disciplinary policies actually get applied to individuals in implementation settings.

To illuminate the relationship between race and the application of punitive policy tools, we analyze sanction patterns in the Temporary Assistance for Needy Families (TANF) program. When federal lawmakers passed welfare reform in 1996, they required states to develop procedures for sanctioning TANF clients. Sanctions are penalties that suspend all or part of a family's benefits for failing to comply with a program requirement. Although they have existed as a policy tool in the welfare domain for many years, they have taken on a more central programmatic role since 1996, as clients have confronted stricter work obligations, narrower exemption criteria, expanded behavioral requirements, and stronger penalties for noncompliance (Hasenfeld, Ghose, and Larson 2004). Sanctions impose highly visible, direct material consequences for behavioral infractions. They provide the primary mode of disciplinary action in state TANF programs and, as such, are among the most potent tools that case managers have for influencing client behaviors and pursuing performance goals.

Prior research has shown that states have been significantly more likely to adopt the strictest TANF sanction policies if they have higher proportions of nonwhite recipients (Soss et al. 2001; Fellowes and Rowe 2004). In addition, a casual inspection of government records suggests that such racial dynamics may characterize the sanction implementation process as well. Using data from the U.S. Government Accountability Office (GAO), one can examine the relationship between the racial composition of the welfare caseload and sanction usage in the states that have adopted the strictest sanction policies. Doing so, we find a strong relationship between the percentage of TANF recipients who are black or Latino and the extent to which states impose sanctions (see fig. 1). Figure 1 suggests a relationship between race and sanctioning outcomes, yet these aggregate statelevel data are extremely limited. They do not allow us to determine if states are actually sanctioning black and Latino recipients more often than whites, and they tell us nothing about how, when, and why client race might matter for the use of penalties under welfare reform. Indeed, national data on TANF adults reveal that, compared to whites, black 


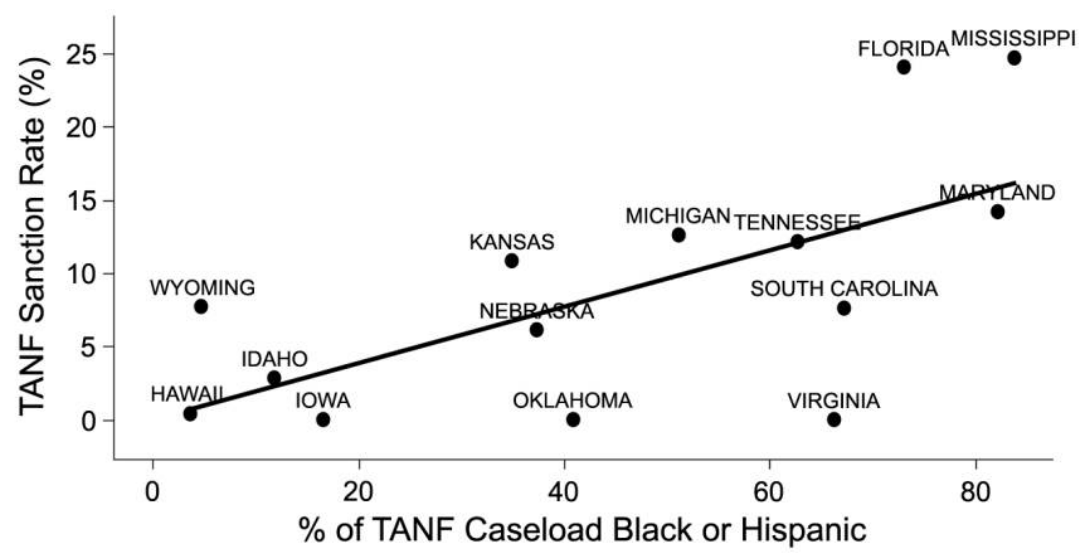

- $\%$ of TANF Adults Receiving Work-Related Sanction

Fitted values

FIG. 1.-Scatterplot of the relationship between the racial/ethnic composition of the Temporary Assistance for Needy Families (TANF) caseload and the work-related sanction rate, FY2002. Note: The sample for this analysis consists of the 14 states that enforced immediate, full-family sanctions in 2002. The horizontal axis is computed as the sum of the percentage of TANF families that are African-American and the percentage that are Latino, based on data reported for April 2002. The vertical axis is the percentage of cases closed due to a work-related sanction during fiscal year 2002. These data are reported in the Sixth Annual Report to Congress, published by the Office of Family Assistance in the U.S. Department of Health and Human Services (http://www.acf.hhs.gov/programs/ ofa/annualreport6/ar6index.htm).

TANF clients tend to have less education, lower earnings, and are more likely to suffer from mental and physical challenges that make it more difficult for black clients to meet TANF work requirements. Thus, to properly investigate the effect of race on sanction decisions, one must examine individual-level data within a research design that maximizes our ability to understand if and why racial disparities exist in sanction implementation.

Drawing on a general model of racial classification and policy choice, we begin our investigation by developing the logic underlying four hypotheses regarding client race and sanctioning in the TANF program. We then proceed to test our hypotheses by using two complementary data sets. We begin with an analysis of longitudinal data on TANF clients from the state of Florida's Welfare Transition (WT) program, a highly decentralized welfare-to-work program funded by the TANF block grant. As the centerpiece of federal welfare reform in 1996, state TANF programs have been at the heart of the recent turn toward paternalist social policy. 
The Florida WT program, in turn, has been at the leading edge of state efforts to use sanctions as a tool to motivate behavioral compliance and change (see fig. 1). Based on a series of longitudinal, multilevel analyses of individual-level administrative data, we find race to play a significant role in sanction implementation; however, the effect is highly contingent on client characteristics and the local political context.

One important explanation for the effect of race in Florida, we argue, is the highly decentralized setting in which sanctions are implemented. Yet, it is impossible to test this hypothesis by examining data from Florida alone. For this reason, we supplement our analysis of the timing of sanctions in Florida with a cross-sectional analysis of TANF sanctioning that relies on a national data set. Such an analysis allows a direct test of the mediating role of administrative decentralization on the effect of race, while also allowing us to provide a partial replication of our results from Florida. Among the states in which TANF is administered by local governments, our findings are largely consistent and suggest that race has played an important role in sanction implementation; however, once again this effect is conditioned by the local political environment. Where TANF administration is more centralized, we find race to be unrelated to sanctioning. In sum, our findings buttress prior research that demonstrates how race has influenced the rolling out of a more disciplinary regime of U.S. poverty governance, both across the states (Soss, Fording, and Schram 2008) and by frontline case managers (Schram et al. 2009).

\section{POLITICS, CHOICE, AND THE IMPLEMENTATION OF TANF SANCTIONS}

A variety of studies have used administrative or survey data to analyze the client characteristics that correlate with a higher likelihood of being sanctioned. Their findings converge on the conclusion that sanctioned participants tend to resemble long-term welfare participants across a variety of characteristics such as marital status, age, family size, education level, job experience, and most importantly for our purposes, race (Koralek 2000; Westra and Routely 2000; Mancuso and Lindler 2001; Kalil, Seefeldt, and Wang 2002; Pavetti, Derr, and Hesketh 2003; Hasenfeld et al. 2004; Wu et al. 2006).

The existing literature is creative and sophisticated in its use of econometric methods. Yet it is also limited by its attention to only one side of a two-sided transaction. With only a few exceptions (e.g., Keiser, Meuser, and Choi 2004), previous studies have trained their attention on clients and asked, at least implicitly, Who is likely to get sanctioned? As a result, these studies largely ignore the fact that welfare sanctions arise not just 
from client characteristics and behaviors but also from policy choices made by a series of political actors, such as state and local representatives, program directors, supervisors, and case managers. The rate and incidence of sanctioning depend, at least in part, on the decisions such actors make as they set policy, organize administrative practice, and apply general rules to specific instances. In short, research to date has largely failed to address sanctions as tools of governance that may or may not be deployed depending on what officials choose in particular jurisdictions and cases.

The sanctions deployed at the frontlines of welfare agencies are products of choice at numerous levels of governance. Under federal welfare reform, states confronted a range of options in designing their sanction policies. By the late 1990s, 17 adopted "immediate full-family sanctions," which suspend all benefits for all members of the TANF family as penalty for the first instance of noncompliance. Fifteen chose "gradual full-family sanctions," which can eventually rise to a "full-family" impact but only after a progression of penalties. The remaining states selected "partial sanctions," which reduce only a portion - typically the adult portion—of the family's benefits (Pavetti et al. 2003). Studies suggest that these choices have been quite consequential, and, as a result, the decline in the welfare caseload has been as much as $25 \%$ greater in states with immediate fullfamily sanctions compared to states with the least punitive sanction policies (Rector and Youseff 1999).

The politics of policy choice is equally crucial at the local level, where a variety of officials hold responsibility for interpreting state sanction policy and specifying it through rule making. Many state governments have practiced "second-order devolution," where primary authority over TANF policy has been devolved to county government officials or regional workforce boards (Gainesborough 2003). In all states, however, local TANF officials are likely to have substantial discretion over program elements that affect the rate and incidence of sanctioning. Their local policy choices typically establish the process by which clients are informed of TANF rules and penalty procedures; the mode of monitoring participation in required activities; the steps for initiating a sanction, including how and when clients are notified of an impending sanction and the steps needed to avoid it; and the procedures and requirements for "curing" a sanction and returning a client to the TANF rolls. Not surprisingly, given the wide scope of this discretion, field studies find that, even when TANF offices operate under the same state guidelines, sanction philosophies and practices vary dramatically across local communities (Pavetti et al. 1998).

State and local policy choices combine to create the settings for more proximate decision processes in the interactions between case managers and clients. As frontline workers, case managers exercise significant discretion in interpreting program rules and applying penalties (Pavetti et 
al. 2003, p. 6; Meyers et al. 2006). Their decisions can influence sanction patterns in a variety of ways. From the outset, case managers are responsible for assessing client needs and capabilities. They identify which clients should be relieved of certain work requirements or told to attend special classes. In doing so, the case manager establishes particular sanctioning parameters for particular clients. And, of course, it is the case manager who must decide ultimately whether to initiate sanction procedures in response to an infraction and whether the circumstances of the infraction justify a "good cause" exception to the rules.

The exercise of discretion by case managers is enhanced by the relative ineffectiveness of traditional monitoring strategies. Case managers rarely operate under the direct watch of supervisors (Prottas 1979), and they process cases at rates that make continual consultation impractical (Maynard-Moody and Musheno 2003). While general rules do place broad limits on case managers, they cannot be designed to cover all conceivable situations. Finally, political economy approaches to social work theory argue that welfare clients occupy a dependent position in a relationship defined by unequal control of power resources (Hasenfeld 1987). Under the TANF program, moreover, clients have lost entitlement status as well as some formal rights of appeal-developments that seem likely to have further weakened clients' abilities to impose limits on caseworker discretion (Mink 2002).

Recognizing the weakness of these constraints, most scholars agree that "discretion is inevitable" in street-level work (Maynard-Moody and Musheno 2000, p. 329) and may be influenced by two sets of factors. On the one hand, the personal values of frontline workers are likely to play a significant role in the many choices and decisions that they make during the implementation process. However, the exercise of discretion may also be influenced by values and incentives reflected in the organizational culture. This is especially likely to be an important factor to consider in understanding the implementation of TANF sanctions, due to the widespread emphasis on caseload reduction and work participation and the organizational pressures to realize these goals in the new performancedriven system (Ridzi 2004; Soss, Fording, and Schram, in press). ${ }^{2}$ In short, sanctions can be understood not just as events that happen to some clients

\footnotetext{
${ }^{2}$ Based on our field research in Florida, we find that performance measurement has had a profound effect on the organizational culture of the local welfare bureaucracy. Indeed, our interviews with case managers and administrators reveal tremendous pressure to meet performance benchmarks, which has likely led to a strong emphasis on sanctions as a tool for regulating client behavior. In addition, the evidence suggests that this emphasis on discipline may have come at the expense of client needs and has likely led to an exacerbation of race and class disparities in sanctioning and client well-being (Soss et al., in press).
} 
more than others (as in most of the current literature) but also as outcomes of governmental decision-making processes. From this perspective, the analytic focus shifts from an investigation of client characteristics per se to an investigation of how client characteristics become relevant to administrative decisions and interact with the environmental forces that systematically shape administrative behavior. In what follows, we pursue exactly this approach, investigating how client racial characteristics combine with stereotype-consistent cues, local political environments, and decentralized administrative structures to influence frontline decisions to impose sanctions.

\section{RACIAL CLASSIFICATION AND THE LOCAL POLITICS OF PUNISHMENT}

Our analysis is based on a simple but general model of social policy choice called the racial classification model (RCM). The RCM draws Schneider and Ingram's $(1993,1997)$ work on the social construction of target populations together with models of implicit racism (Quillian 2008) to clarify the unconscious ways that racial schemas can guide interpretation and choice. The RCM specifies conditions that can produce policy-based racial disparities even in the absence of overt racial animus or discriminatory intent. In this sense, it is a minimalist cognitive model of policy decision making that focuses on the necessity of social classification and the resulting consequences of group reputation. The RCM does not preclude the operation of overt prejudice. Rather, it suggests how implicit cognitive processes function to produce racial disparities even in circumstances where overt prejudice and discriminatory intent are not observed. Here, we apply the model to policy implementation settings by deriving four hypotheses regarding TANF sanctions. The RCM consists of three basic premises (see Soss et al. 2008):

1. To be effective in designing policies and applying policy tools to specific target groups, policy actors must rely on salient social classifications and group reputations; without such classifications, they would be unable to bring coherence to a complex social world or determine appropriate action.

2. When racial minorities are salient in a policy context, race will be more likely to provide a salient basis for social classification of targets and, hence, to signify target differences perceived as relevant to the accomplishment of policy goals. 
3. The likelihood of racially patterned policy outcomes will be positively associated with the degree of policy-relevant contrast in policy actors' perceptions of racial groups. The degree of contrast, in turn, will be a function of $(a)$ the prevailing cultural stereotypes of racial groups, $(b)$ the extent to which policy actors hold relevant group stereotypes, and $(c)$ the presence or absence of stereotype-consistent cues.

Although policy actors are surely guided by many motives, the RCM suggests that they generally try to choose courses of action that they expect to be effective in light of what they believe about the specific groups they aim to address. In this process, social group characteristics can serve as proxies for more detailed information about a policy's intended target group. When race is salient to a policy area, as in the case of welfare (Gilens 1999), racial classifications can serve precisely this function, regardless of whether racial animus is present and regardless of the decision maker's own racial identity. In such cases, group reputations can frame interpretations of ambiguous policy-target behaviors and cue assumptions about the kinds of policy actions that are likely to be effective. The effects of a particular group reputation, however, will depend on the policy relevance of its contents and on situational factors that may strengthen or weaken its utility as an information proxy (Schram et al. 2009).

In applying the RCM to TANF sanction decisions, we conceptualize sanctions as tools for motivating welfare clients, stimulating work effort, and enforcing responsible behavior. ${ }^{3}$ Accordingly, local policy actors should be more likely to organize and implement sanctions in a stringent fashion when TANF clients are perceived as less motivated and responsible in their own right - that is, when clients are perceived as needing a stronger external stimulus to follow program rules and achieve welfareto-work goals. In this context, client race should affect sanctioning patterns to the extent that contrasts between racial-group reputations convey information about motivation, work effort, and personal responsibility.

Combining these assumptions with research on group stereotypes in the United States, we can derive our first hypothesis from the RCM. Relative to white Americans, black Americans remain strongly associated

\footnotetext{
${ }^{3}$ We do not mean to suggest that sanctions are necessarily effective in achieving these goals, although the existing research does suggest that full-family sanctions (compared to partial sanctions) are more likely to promote work exits and caseload decline (for a review of this research, see Pavetti et al. [2003]; Meyers et al. [2006]). Rather, we assume that case managers and welfare administrators believe that sanctions are effective at achieving these goals. Of course, these goals have very little to do with client well-being and self-sufficiency. Indeed, the research on this question suggests that if sanctions have any effect on well-being, the effect is negative (Pavetti et al. 2003; Meyers et al. 2006).
} 
with low work effort and motivation, socially irresponsible behavior, and preferences for welfare reliance (Schuman et al. 1997; Gilens 1999). Stereotypes of Latinos occupy a midpoint, less negative than blacks but more negative than whites (Fox 2004). ${ }^{4}$ Accordingly, the RCM suggests:

Нyротнеsis 1.-Simple disparity hypothesis: all else equal, TANF officials will be more likely to sanction black clients than white or Latino clients and more likely to sanction Latino clients than white clients.

As a baseline hypothesis, hypothesis 1 suggests that client race will have a significant and equivalent effect in all circumstances. Because adult men make up such a small percentage of welfare recipients, the most relevant group contrasts here focus on images of white, black, and Latino poor women. As students of intersectionality have rightly emphasized, the cultural images that attach to such compound identities often deviate in significant ways from the stereotypes that surround a single axis of social stratification, such as gender or race taken alone (Collins 2005; McCall 2005; Hancock 2007; Strolovitch 2007). In the welfare context, arguably the most powerful "controlling images" have focused on poor black women, portraying them as sexually promiscuous jezebels and as mammies who are expected to work outside their own families but tend to shirk their responsibilities when left to their own devices (Hancock 2004; Collins 2005; Jordan-Zachery 2008). Indeed, in an analysis of survey data reported elsewhere, we find that sexual stereotypes of black women influence public attitudes toward welfare policy in ways that stereotypes of black men do not (Soss et al., in press).

The third proposition of the RCM, however, suggests that such controlling images should have contingent rather than invariant effects, with the impact of client race depending on both the degree to which policy actors hold relevant group stereotypes and the presence or absence of particular stereotype-consistent cues (regarding laziness, sexual promiscuity, or other prominent stereotypes regarding subgroups of welfare recipients). These elements of the RCM allow us to move beyond simple disparities to specify and test more nuanced hypotheses. As intersectionality research underscores, two individuals who are perceived as members of the same racial group - even if they are both women-may nevertheless be associated with quite different group reputations. Social cognition researchers have shown that perceivers tend to distinguish "subtypes" of racial groups (such as "ghetto blacks" vs. "black businessmen") and to attribute negative global-group traits to these subtypes to very different degrees (Devine and Baker 1991; Richards and Hewstone 2001). As a

\footnotetext{
${ }^{4}$ We restrict our attention to white, black, and Latino welfare recipients due to the fact that, in our data sample, sizes are too small for other racial and ethnic groups at the county level.
} 
result, race-of-target effects will often be contingent on additional characteristics that strengthen or weaken the individual's connection to the group's prevailing reputation. Eberhardt and colleagues (2006), for example, find that black defendants convicted of killing white victims are more likely to receive the death penalty if they are perceived as having a "stereotypically black appearance."

Prior research suggests that a variety of stereotype-consistent cues can enhance race-based disadvantages. In some instances, this effect functions to widen already-existing racial disparities. In others, it creates disparities where none had otherwise existed. The former scenario is well illustrated by Pager's (2003) influential field experiment exploring the effects of race and "the mark of a criminal record" on hiring outcomes. Pager (2003) finds that black job applicants are already disadvantaged relative to whites in the no-felony condition of her experiment, yet the attribution of a felony conviction actually reduces black applicants' job prospects to a greater degree than the prospects of already-advantaged white applicants. By contrast, the latter scenario is illustrated by a recent study of how racial cues affect preferences for political candidates. Valentino, Hutchings, and White (2002, p. 86) find that "when the black racial cues are stereotype-inconsistent, the relationship between racial attitudes and the vote disappears. . . . [Likewise] the presence of black images alone . . . does not prime negative racial attitudes. . . The effect emerges only when the pairing of the visuals with the narrative subtly reinforces negative stereotypes in the mind of the viewer."

Building on this research, the RCM suggests that, regardless of whether simple racial disparities exist, the presence of a trait that is consistent with stereotypes of poor minority women should increase the odds of a sanction more for minority clients than for white clients. In the present analysis, perhaps the most relevant trait of this sort is long-term welfare usage (Gilens 1999). For several decades now, welfare "dependency" has been a prominent stereotype associated with poor racial minorities-interpreted in various quarters as a distinguishing feature of "underclass" culture, a pathology akin to addiction, and a clear sign of an individual's unwillingness to work (Schram 1995). This image has been particularly salient for poor black women in welfare programs, whose "laziness and dependence" have been portrayed as a civic failure as well as an abdication of maternal responsibility (Hancock 2004; Mead 2005). To stay on the welfare rolls for a comparatively long period is, in the context of welfareto-work programs, to mark oneself in a policy-relevant and racially inflected way. Accordingly, the RCM suggests:

Нyротнеsis 2.-Time-contingent disparity hypothesis: the effects of race on sanctioning will grow stronger, and, thus, the racial disparities 
predicted under hypothesis 1 will grow larger, as TANF participation spells increase in length.

The third premise of the RCM predicts that the production of racial disparities will also be contingent on the extent to which policy actors hold relevant group stereotypes. When such stereotypes are viewed with skepticism, racial-group reputations will be perceived as poor proxies for more detailed information and, hence, as unreliable guides to decisions regarding policy targets. By contrast, when such stereotypes are accepted as largely valid, differences in group reputation should convey more useful information and, thus, the likelihood of racially patterned outcomes should increase.

Ideally, one would test this component of the RCM by utilizing direct measures of stereotype acceptance at the individual level. In the absence of such measures, one must seek out a suitable proxy by asking where in American society one is likely to find greater acceptance of stereotypes regarding racial-group orientations toward work and welfare. As an empirical matter, one answer to this question is that such stereotypes are more likely to be found in politically conservative communities than in politically liberal communities. There is, of course, no logical reason why conservatives should hold more negative views of racial minorities. Indeed, there are good reasons to distinguish between the two when trying to explain public opposition to various policies designed to advance egalitarian goals (Sears, Sidanius, and Bobo 2000). Nevertheless, two basic empirical observations emerge as uncontroversial in the existing literature. First, conservatives are more likely than liberals to oppose welfare and to hold negative views of welfare recipients (Cook and Barrett 1992; Gilens 1999). Second, conservatives are more likely than liberals to hold negative stereotypes of African-Americans, especially in assessing the degree to which blacks and Latinos are "lazy" compared to other racial groups (Glaser 1994; Johnson and Marini 1998; Gilens 1999; Oliver and Mendelberg 2000; Domke 2001; Federico and Sidanius 2002).

This relationship can be easily documented with data from the National Election Study (NES). In recent years, the NES has asked respondents to evaluate the degree to which different racial and ethnic groups (including blacks, Latinos, and whites) were either "hard working" or "lazy" (on a seven-point scale). We first computed a measure of the black-white and Latino-white "stereotype gap" by subtracting the laziness score for whites from the black and Latino scores, respectively. We then regressed the stereotype gap for each minority group on a measure of conservatism. The predicted regression line from these two bivariate regressions is plotted in figure 2, based on pooled NES data from 1996, 2000, and 2004. ${ }^{5}$

\footnotetext{
${ }^{5}$ Supplementary analysis finds that the relationship between the black and Latino
} 


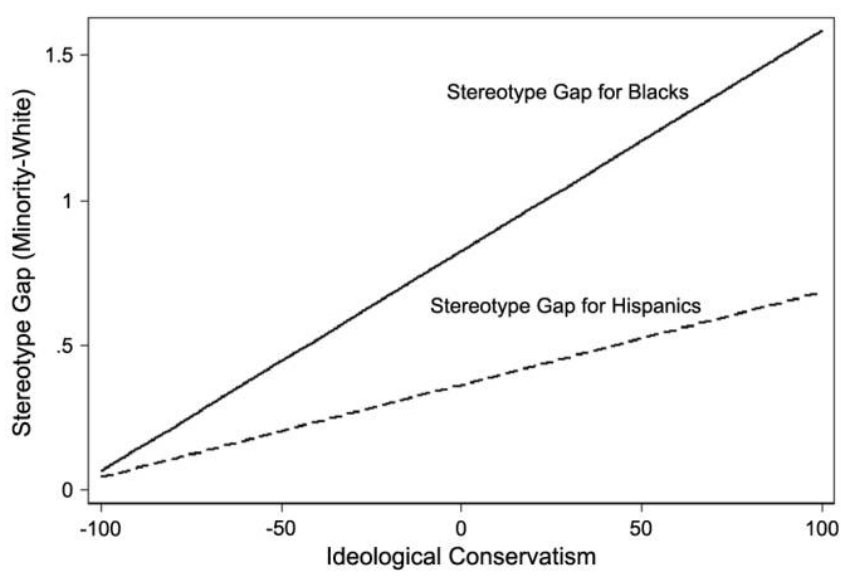

FIG. 2.-Average gap in perceived laziness of racial groups, by ideological identification of respondents. Note: The vertical axis is the stereotype gap and is computed as the difference in the mean assessment of laziness for each pair of target groups (the mean score for blacks/ Latinos minus the mean score for whites), where the laziness scale is coded as follows: $1=$ hardworking, 7 = lazy. As scaled, the stereotype gap is a measure of the degree to which respondents view blacks (or Latinos) as lazier than whites. The measure of conservatism is computed as the feeling thermometer score for conservatives minus the score for liberals. The lines in the graph represent the predicted relationship between conservatism and the stereotype gap for each group, based on a bivariate regression that utilizes pooled data from the National Election Study (1996, 2000, 2004). Each slope value is statistically significant $(P<.01)$.

The results are clear. Conservatives are more likely than liberals or moderates to view blacks and Latinos as lazy, compared to whites. As a result, the perceived gap between group reputations grows consistently larger as one shifts from the liberal to the conservative end of the ideological spectrum. One need not engage the thorny causal questions of why this relationship exists to pursue our present analytic goals. It suffices to say that there is an empirical basis for assuming that, in more conservative political environments, one is more likely to find negative views of welfare

stereotype gaps and conservatism is robust across different time periods and regions of the United States. The data necessary to conduct this analysis are unavailable in the NES prior to 1996. However, we were able to use General Social Survey (GSS) data to estimate the relationship between the black and Latino stereotype gaps and a simpler measure of conservatism for all GSS years since 1990. The results are consistent with the analyses presented in fig. 2. We also estimated the relationship separately for each of the four census regions. For blacks, the relationship is relatively stable and statistically significant in each of the four census regions. For Latinos, the relationship is statistically significant in the South and West regions at the .05 level and close to significance in the Northeast and North Central regions. These results are summarized in appendix tables A1-A11 and figs. A1-A5 in the online edition of the journal. 
reliance and acceptance of stereotypes asserting that racial minorities differ from whites in preferring welfare over work.

Combining this observation with the RCM leads to the expectation that racial disparities in sanctioning will be larger in more politically conservative communities. A variety of mechanisms may underlie this relationship. Because case managers tend to be drawn from local communities, one would expect them to be more conservative (and, hence, more likely to perceive racial-group differences in welfare-work orientations) when their offices are located in more conservative environments. The same selection dynamics are likely to operate for TANF supervisors, program directors, and governing-board members. As a result, racial disparities in sanctioning may arise more often in conservative communities, not only due to the attitudes of individual case managers but also because racial classifications have guided the more senior officials who set local operating procedures and manage TANF implementation. Finally, because welfare agencies are "open systems" that must respond to their political environments (Meier 1993), conservative and liberal communities may produce different patterns of program implementation because of the ways that racialized understandings inform political pressures, standards of legitimacy, and agendas for action. For all these reasons, the RCM suggests:

НуротHesis 3.-Ideology-contingent disparity hypothesis: the effects of race on sanctioning will be stronger, and, thus, the racial disparities predicted under hypothesis 1 will be larger, in conservative political environments.

Finally, we offer a fourth hypothesis which predicts that the causal mechanisms assumed by the RCM will have the strongest effect on implementation outcomes in administrative environments that offer greater discretion to local decision makers and frontline workers. As discussed above, many states have devolved significant authority in TANF implementation to local governments or regional workforce boards-a process known as second-order devolution (SOD) (Gainsborough 2003). Under SOD, states grant administrative authority to local governments just as the federal government grants authority and responsibility to state governments in designing and implementing TANF (Nathan 1996; Adkisson 1998). Although the division of state-local responsibility varies across SOD states, it is generally agreed that in SOD states, local TANF administrators and frontline staff enjoy greater freedom from state control and thus have the opportunity to exercise significantly greater discretion in TANF implementation (Fording, Soss, and Schram 2007). Therefore, racial classifications may have more room to influence local decision making in SOD states, raising the odds of racial disparities in sanctioning outcomes. This leads to our final hypothesis:

Hyротнеsis 4.-Decentralization-contingent disparity hypothesis: the 
effects of race on sanctioning will be stronger, and, thus, the racial disparities predicted under hypothesis 1 will be larger, in states that have chosen to engage in second-order devolution.

To date, we are aware of only one study that has examined the effects of both race and the political environment on TANF sanctioning. Keiser, Meuser, and Choi (2004) analyze administrative data on sanctioning in Missouri, finding that after one controls for relevant client-level and county-level factors, blacks are, on average, $23 \%$ more likely to be sanctioned than white recipients. Moreover, the authors find that the magnitude of racial differences varies across seven geographic regions in a pattern that they interpret as politically meaningful. Yet, as a test of the RCM's predictions, Keiser and colleagues' analysis has significant limitations.

Because of small sample sizes, the authors could only examine how racial effects varied across a small number of geographic groupings (seven), all of which were defined at a high level of aggregation and some of which were noncontiguous. As a result, they were unable to test whether differences in racial effects correlated with any direct measure of political ideology (hypothesis 3). In addition, because Keiser and colleagues relied on binary logit analysis rather than event history analysis, they were unable to test hypotheses related to spell length (hypothesis 2), and their analysis of racial disparities offered only a limited ability to control for differences in at-risk periods across groups (see Wu et al. 2006). Finally, by examining a single state operating in a centralized administrative environment, not only is their analysis limited in external validity, it cannot test for differences in racial effects due to variation in administrative decentralization (hypothesis 4).

Our analysis follows Keiser, Mueser, and Choi (2004) in that we examine the individual and contextual determinants of sanctioning using administrative data. However, we build on their analysis in several important ways. First, by examining sanctioning in the state of Florida, where the minority population is not only sizable but widely dispersed, we are able to examine racial effects across a large number of geographic contexts at a lower level of aggregation that is both administratively and politically meaningful (the county). As a result, we can directly test the interaction of local political ideology and client racial characteristics. Second, because Florida is a racially diverse state, we are able to examine disparities in sanctioning across blacks, whites, and Latinos. Third, by modeling sanctions using an event history design, we are able to control for group differences in at-risk periods and directly test the hypothesis that racial disparities will grow across the length of the welfare spell. And, finally, by extending our analysis to national data on TANF sanctions, we are not only able to test for the effects of administrative decentralization but 
we are able to provide a level of external validity that is absent in prior studies of sanctioning.

\section{RACE AND SANCTIONING IN THE FLORIDA TANF PROGRAM: AN ANALYSIS OF ADMINISTRATIVE DATA}

We have selected the Florida WT program for our study, not because it is typical of all state TANF programs but because it provides close to an ideal setting for analyzing how race and politics affect local differences in the use of penalties. Since 1996, Florida, as a practitioner of "secondorder devolution," has constructed one of the most decentralized TANF programs in the country. Frontline services have been contracted out to public, nonprofit, and for-profit providers throughout the state, and primary authority over the WT program has shifted down to 24 local public/ private "regional workforce boards" (RWBs). These RWBs are responsible for strategic planning, policy development, contracting, and oversight of local one-stop delivery systems. Several of the regions encompass more than one county, and the regional boards set policy in a way that allows for county offices to have some discretion in implementing policies. The regional boards are overseen not by state agencies but by a statewide public/private partnership called Workforce Florida, Inc. (WFI). The Florida Department of Children and Families (DCF), a conventional state agency, receives the federal TANF block grant and maintains responsibility for eligibility determination. But otherwise, Florida stands out among American states for its emphasis on local control and privatization within a work-oriented TANF program (Botsko, Snyder, and Leos-Urbel 2001, p. 7).

Florida also scores high on factors that raise the importance of sanction decision processes. After 1996, Florida adopted "some of the strictest time limits and work requirements in the nation" and broadened the pool of clients subject to sanctions by creating "few possibilities for exemptions" (Botsko et al. 2001, p. 4). The sanctions themselves also fall at the strong end of the continuum, resulting in an immediate, full-family loss of TANF benefits and a reduction of food stamp benefits to the fullest extent permitted by federal law (Botsko et al. 2001, p. 6). Moreover, as we can see in figure 1, Florida employs sanctions at an extremely high rate compared to other states with full-family sanctions.

The selection of Florida also aids our analysis because it offers significant variation on the two most critical independent variables in our study: race and local political environment. Florida is one of the most racially diverse states in the country, with sizable black and Latino populations, and the state's TANF population displays even more diversity. Between 
January 2000 and March 2004, 36.2\% of TANF adults were black, 33.7\% were white (non-Latino), and $28.5 \%$ were Latino. In addition, Florida is a politically diverse state, a fact clearly reflected in recent presidential elections. In combination with Florida's heavy emphasis on sanctioning and decentralized approach to welfare provision, this variation in race and ideology provides an ideal setting for a study of the joint effects of race and ideology on local sanction implementation.

\section{Data and Methods}

Our sample consists of individual-level administrative data for all new adult TANF clients who entered WT during the 24-month period from January 2001 through December 2002, supplemented with contextual data indicating how local implementing environments vary across the state's 67 counties. ${ }^{6}$ Thus, our entire period of analysis extends from January 2001 (first cohort enters) through November 2003 (12th month of spell for last cohort). We follow each of the 24 cohorts for up to a maximum of 12 consecutive months, ending our observations of the case at the spell's termination or at the 12 -month mark, whichever comes first. We restrict our attention to the first TANF spell for each individual during this period, defined based on continuous months of TANF receipt. As defined, and accounting for cases for which values on some variables are missing, our total sample size includes approximately 70,000 individuals who were subject to over 26,000 sanctions across approximately 200,000 personmonth observations. ${ }^{7}$

As our data consist of variables that are measured at two levels of analysis (individual and county), we examine the determinants of sanction usage by employing a discrete-time multilevel event history analysis of the initiation of a sanction (Barber et al. 2000). Our dependent variable is Sanction $_{t j k}$ - a dichotomous variable that indicates whether or not client $j$, residing in county $k$, has been sanctioned in month $t$. We estimate our model using the logit link (i.e., as a hierarchical generalized linear model, or HGLM), and therefore the effects of the independent variables are

\footnotetext{
${ }^{6}$ We define "new" TANF clients as those clients who have spent at least 12 continuous months without TANF benefits.

${ }^{7}$ We are missing data on the age of TANF children ( $7 \%$ of cases) and for the education level of TANF adults (29\% of adults). Yet, a comparison of sanction rates of missing and nonmissing cases finds the difference to be trivial $(38.1 \%$ for nonmissing cases, $37.3 \%$ for missing cases), and therefore we are not concerned that the omission of these cases has led to significant bias in our statistical estimates. In addition, we find relatively little difference between missing and nonmissing cases for most independent variables as well. A more detailed comparison of missing and nonmissing cases for our Florida sample is included in the online appendix.
} 
additive and represent the change in the log odds of sanction. The independent variables include individual-level measures capturing client effects and county-level measures capturing community-context effects. ${ }^{8}$ The individual-level (level 1) model is represented below in equation (1):

$$
\begin{aligned}
& \text { Sanction }_{t j k}=\beta_{0 k}+\beta_{1 k} \text { Black }_{j}+\beta_{2 k} \text { Latino }_{j} \\
& +\beta_{3 k}\left(\text { Black }_{j} \times \text { Month of } \operatorname{Spell}_{t j}\right), \\
& +\beta_{4 k}\left(\text { Latino }_{j} \times \text { Month of Spell }_{t j}\right)+\beta_{5 k} \text { No. Children (2) }{ }_{j} \\
& \left.+\beta_{6 k} \text { No. Children (3 or more) }\right)_{j} \\
& \left.+\beta_{7 k} \text { Age of Youngest Child (3 mos. }-2 \text { yrs. }\right)_{j} \text {, } \\
& \left.+\beta_{8 k} \text { Age of Youngest Child (3-4 yrs.) }\right)_{j} \\
& +\beta_{9 k} \text { Age of Youngest Child (5-11 yrs.) } \text {, } \\
& +\beta_{10 k} \text { Age of Youngest Child (12 yrs.or more) }{ }_{j} \\
& \left.+\beta_{11 k} \text { Education (H.S. }\right)_{j}+\beta_{12 k} \text { Education }(>\text { H.S. })_{j} \text {, } \\
& +\beta_{13 k} \text { Male }_{j}+\beta_{14 k} \text { Citizen }_{j}+\beta_{15 k} \text { Age }_{j}+\beta_{16 k} \text { SingleParent }_{j} \\
& +\beta_{17 k} \text { Earned Income }_{j}+\beta_{18 k} \text { Month } 2_{t j} \text {, } \\
& +\beta_{19 k} \text { Month } 3_{t j}+\beta_{20 k} \text { Month } 4_{t j}+\beta_{21 k} \text { Month } 5_{t j} \\
& +\beta_{22 k} \text { Month } 6_{t j}+\beta_{23 k} \text { Month } 7_{t j}+\beta_{24 k} \text { Month } 8_{t j} \text {, } \\
& +\beta_{25 k} \text { Month } 9_{t j}+\beta_{26 k} \text { Month } 10_{t j}+\beta_{27 k} \text { Month } 11_{t j} \\
& +\beta_{28 k} \text { Month } 12_{t j} \text {. }
\end{aligned}
$$

An important feature of a multilevel model is that the coefficients for the level 1 variables (the $\beta \mathrm{s}$ in eq. [1]) are permitted to vary across our level 2 units (counties). Based on theoretical expectations, the county-level variables therefore enter the level 2 model as explanatory variables for these effects. Our level 2 model is reflected below in equations (2)-(5) and reflects our theoretical expectations concerning the effects of county-level variables on the intercept $\left(\beta_{0 k}\right)$ of equation (1) (i.e., the mean rate of sanctioning across counties) and on the slope values for Black and Latino (i.e., $\beta_{1 k}$ and $\beta_{2 k}$ ):

\footnotetext{
${ }^{8}$ We provide detailed variable descriptions, including data sources and descriptive statistics, for each variable used in the analyses that follow in the online appendix.
} 
American Journal of Sociology

$$
\begin{gathered}
\beta_{0 k}=\gamma_{00}+\gamma_{01} \text { Local Conservatism }_{k}+\gamma_{02} \text { OBlack }_{k} \\
+\gamma_{03} \% \text { Latino }_{k}+\gamma_{04} \text { Annual Wage }_{k} \\
+\gamma_{05} \text { Unemployment Rate }_{k}+\gamma_{06} \text { Poverty Rate }_{k} \\
+\gamma_{07} \text { Population }_{j}+\gamma_{08} \text { TANF Caseload }_{j}, \\
\beta_{1 k}=\gamma_{00}+\gamma_{01} \text { Local Conservatism }_{k}+\epsilon_{1 k}, \\
\beta_{2 k}=\gamma_{00}+\gamma_{01} \text { Local Conservatism }_{k}+\epsilon_{2 k}, \\
\beta_{p k}=\gamma_{p 0}, \text { for } p=3-28 .
\end{gathered}
$$

\section{Level 1 Hypotheses}

To test the simple disparity hypothesis, we classify clients as belonging to one of three mutually exclusive racial/ethnic group combinations: black, Latino, and white (non-Latino). ${ }^{9}$ We then include the dichotomous variables Black and Latino in our model of sanction initiation, where we expect the coefficient values in equation (1) will be positive for each of these variables $\left(\beta_{1}, \beta_{2}>0\right)$, and the coefficient for Black will be larger than the coefficient for Latino $\left(\beta_{1}>\beta_{2}\right)$. We test the time-contingent disparity hypothesis by including two interaction terms in equation (1), Black $\times$ Month of Spell and Latino $\times$ Month of Spell, where we expect that the coefficients for these variables will be positive $\left(\beta_{3}, \beta_{4}>0\right)$.

Based on past research on sanctions and welfare implementation, we include a number of other variables to control for variation in clients' individual characteristics. These include variables measuring the client's sex (Male), citizenship status (Citizen), and age (Age). The age of the youngest child in the TANF family is measured by a series of categorical variables, as is the number of children in the TANF family. We include the client's marital status (Single Parent), and two indicators of human capital (Earned Income and Education). All of these variables have been found to be important determinants of individual sanctioning outcomes in past research (Mancuso and Lindler 2001; Kalil et al. 2002; Hasenfeld et al. 2004; Wu et al. 2006).

Finally, we include a series of dummy variables for each month of the spell to model the baseline hazard of sanction. This strategy has the advantage of leaving the shape of the baseline hazard function unspecified,

\footnotetext{
${ }^{9}$ We omit a very small percentage $(<2 \%)$ of cases classified as "other race" by the state.
} 
which in this sense is analogous to the continuous-time formulation of the Cox proportional hazards model (Beck, Katz, and Tucker 1998).

\section{Level 2 Hypotheses}

We model the intercept of equation (1) $\left(\beta_{0 k}\right)$ as a function of several different features of local political, economic, and social environments. Due to the theoretical importance of local ideology for our analysis, we rely on two alternative measurement strategies. First, for each of Florida's 67 counties we coded election results for 18 ideologically relevant constitutional amendments that appeared on the ballot throughout the entire state between 1996 and 2004. Based on a factor analysis of support for all 18 amendments, we used factor scores to create an index of county conservatism that runs from zero (most liberal county) to one (most conservative county). This index is labeled Local Conservatism and serves as our primary measure of the local political environment in Florida. As an alternative measure, we rely on the Republican share of the two-party presidential vote, averaged over three presidential elections (1996, 2000, and 2004). Because partisanship tends to be imperfectly related to political ideology (Miller 1999), we believe our amendment-based measure to be a more valid measure of local ideology. However, as we describe below, our key results are consistent regardless of the indicator we use, enhancing our confidence in the validity of our conclusions. ${ }^{10}$

In addition to local political ideology, we consider one additional dimension of the local political environment: the local racial context. Previous studies have often found that racial context has a significant impact on racially relevant policy outcomes, either through the effects of a "racial threat" felt by the white majority (Key 1949) or the effects of increased minority political power (Keech [1968] 1981). Because there is reason to suspect that either effect might exist (see Keiser et al. 2004), we test for effects of community racial composition by including the percentage of the county population that is black and Latino, respectively (\%Black, $\%$ Latino). ${ }^{11}$

${ }^{10}$ The simple correlation between our measure of county conservatism and our measure of the Republican vote share is reasonably strong at .65. In addition, we have replicated the analysis presented in fig. 2 by substituting a measure of Republican identification for our measure of conservatism, and we find a similar (and statistically significant) relationship. Details concerning this analysis and the construction of our amendmentbased measure of county ideology are provided in the online appendix.

${ }^{11}$ We explored two alternative indicators to test for the effects of the local racial context on TANF sanctioning. First, we utilized the county vote for George Wallace in the 1968 presidential campaign. Second, we used the 10-year change in the black and Latino county population percentage. Neither of these variables proved to have an 
Several additional measures capture the effects of local labor markets and employment opportunities, which we expect to affect sanctioning in one of two ways. First, where employment opportunities are relatively numerous and attractive, TANF clients may be more likely to work enough hours to avoid falling out of compliance with TANF rules. Alternatively, local labor market conditions may also influence the sanction decisions of case managers, who may be less inclined to sanction clients when job opportunities are less numerous or less attractive. To capture such effects, we include the county unemployment rate (Unemployment Rate), the county poverty rate (Poverty Rate), the level of urbanization (as measured by county population-Population), and the annual local wage in food service/drinking establishments (Annual Wage).

We also include a measure of the county TANF Caseload, expressed as a proportion of the county's population. As the caseload size increases, we might expect, all else being equal, that administrative pressures to reduce the caseload would result in an increase in sanctioning. Alternatively, as the caseload size increases, if the number of case managers remains fixed, individual case managers may have less time to closely monitor TANF clients for violations of rules, thus resulting in a lower rate of sanctioning.

Finally, we test the ideology-contingent disparity hypothesis by including Local Conservatism as a predictor for the effects of Black $\left(\beta_{1 k}\right)$ and Latino $\left(\beta_{2 k}\right)$, as reflected in equations (3) and (4). As we expect racial disparities to increase in conservative counties, we expect Local Conservatism to be positively related to the effects of Black $\left(\beta_{1 k}\right)$ and Latino $\left(\beta_{2 k}\right)$, and, thus, $\gamma_{11}$ and $\gamma_{21}>0$.

\section{Results}

Table 1 presents results for two versions of our event history model that differ only in the measure used to capture the local ideological environment. For each version, we report both the coefficient values and the associated odds ratios reflecting the proportional increase in the risk of sanction given a one-unit increase in the independent variable.

We begin by examining the dynamics of sanctioning across the TANF spell, as reflected by the effects of the month-of-spell dummies in equation (1) (which collectively reflect the baseline hazard of sanctioning). For ease of interpretation, we do not report these results in tables 1 and 2 but

effect on the level of TANF sanctioning nor did either exhibit a significant interaction with the race of the client. And perhaps most importantly for the purposes of testing our hypothesis, the inclusion of these alternative indicators did not affect the statistical results in any meaningful way. The results from these alternative specifications are reported in the online appendix. 


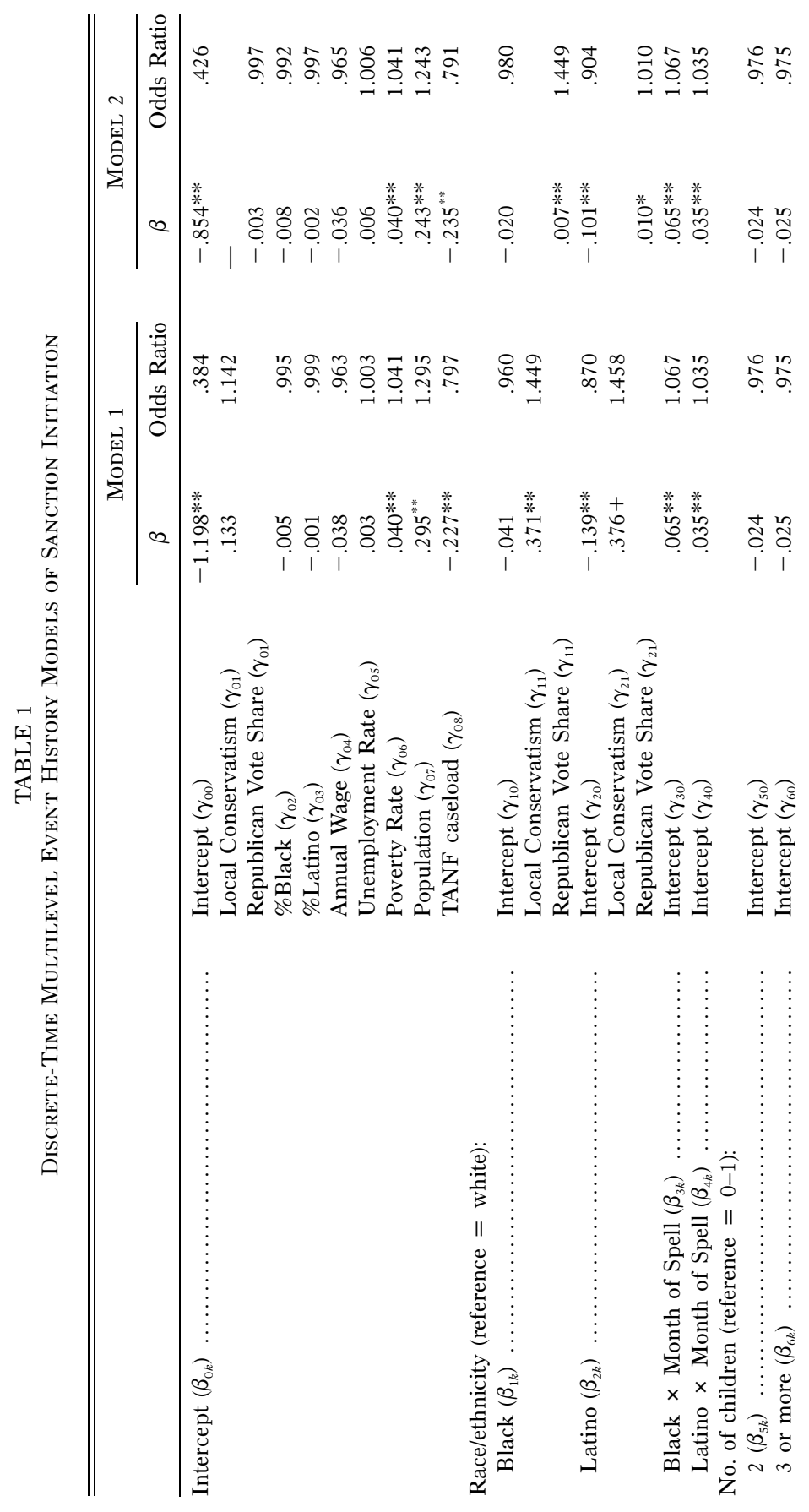




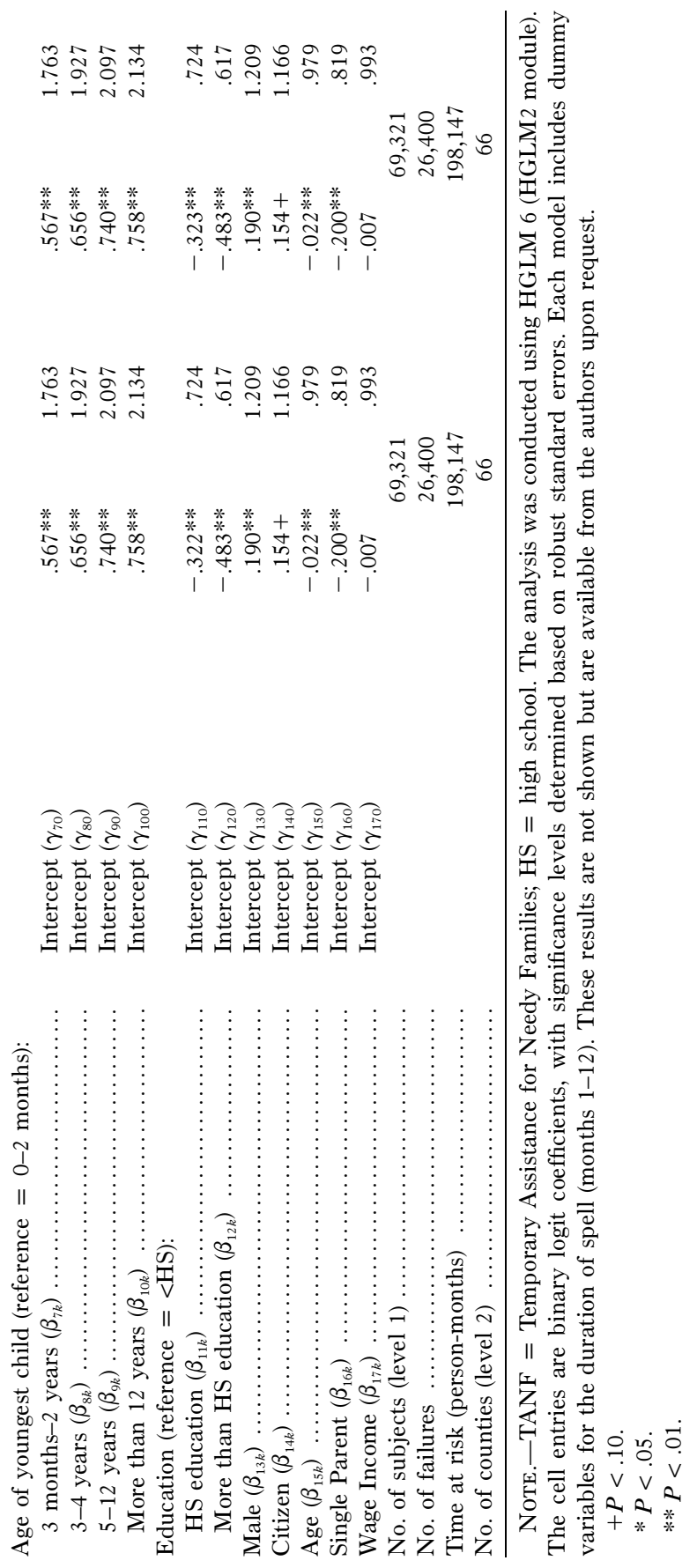


instead present a graphical display in figure 3. The vertical axis of the figure is the odds ratio of sanction, based on the coefficient estimates for equation (1). Thus, for each month of the TANF spell reflected on the horizontal in figure 3 , the associated odds ratio reflects the relative odds of sanction, compared to the initial odds at month 1, for a client who has been on TANF throughout all of the preceding months but has not yet been sanctioned. As can be seen, the risk of sanction steadily decreases throughout the TANF spell. Indeed, by month 5 of the spell the client's risk of sanction has decreased by nearly $50 \%$ compared to month 1 .

Next, we examine the results for our control variables. As expected, we find that sanctions are significantly related to clients' individual traits in both specifications of our model. Specifically, TANF sanctions are significantly more likely to be applied to the small number of men in the program, relative to the large majority of women. The probability of being sanctioned is also higher for clients who are younger, who are heads of two-parent families, who have older children, who are citizens, and who possess less human capital (as measured by education level).

Moving to our contextual variables, sanctioning appears to be significantly heavier in high-poverty counties with large populations, yet significantly lower in counties with large TANF caseloads. We find weaker effects for other aspects of the local economic context: neither unemployment rates nor local wage levels prove to be consistent predictors. Nor do we find higher levels of minority presence in the community to affect local sanctioning rates. In sum, these results are largely consistent with the results of past studies and therefore give us greater confidence in the results we report below (Westra and Routely 2000; Mancuso and Lindler 2001; Kalil et al. 2002; Hasenfeld et al. 2004; Keiser et al. 2004; Wu et al. 2006).

Turning to an examination of our primary hypotheses, we begin with the simple disparity hypothesis predicting that (1) the coefficients for Black and Latino should be positive (reflecting significant black-white and Latino-white disparities in sanctioning), and (2) the coefficient for Black should be larger than the coefficient for Latino (due to the presumed larger gap in group reputations between blacks and whites). As specified, equation (1) models the effects of Black/Latino as interactive, and therefore conditional, on spell duration and the local political environment. To ease interpretation, we transformed Local Conservatism, Republican Vote Share, and Month of Spell by subtracting their means prior to estimation, so that the coefficients for Black and Latino in tables 1 and 2 reflect the effects of race and ethnicity for clients who reside in a politically moderate county and who are at a typical point in the TANF spell (month 3). As can be seen from the coefficient estimates in table 1, we find mixed support for the simple disparity hypothesis. The coefficients for Black are statis- 


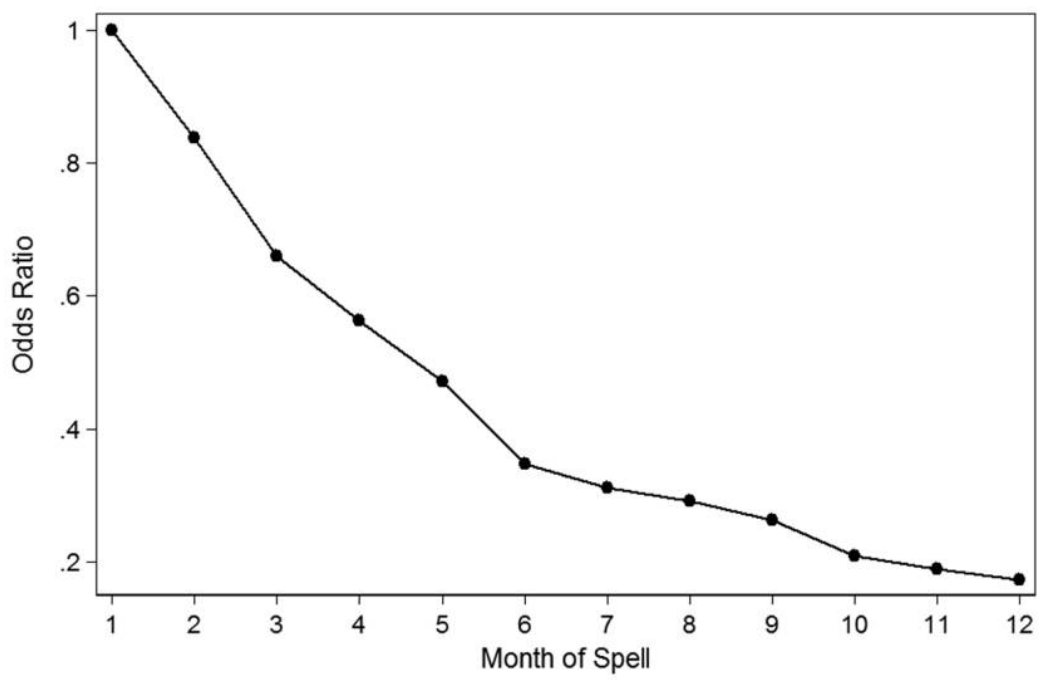

FIG. 3.-Odds ratio of sanction for Florida TANF clients across the TANF spell (baseline $=$ month 1 of TANF spell).

tically insignificant in both specifications, and while the coefficient for Latino is statistically significant, the direction of the effect is the opposite of what is expected and suggests that Latino clients are sanctioned at a rate that is lower than whites and blacks alike. While this is not what we expected, we can think of at least two possible explanations for our findings regarding the simple disparity hypothesis.

First, upon closer inspection, the sanctioning patterns we observe are consistent with the trends in public opinion that we presented in figure 2. Based on the relationship between conservatism and the black and Latino stereotype gaps, we see that stereotype gaps virtually disappear among the most liberal respondents. Even more relevant, perhaps, when we restrict the analysis presented in figure 2 to the states with the largest Latino populations (California, Florida, and Texas), the stereotype gap for Latinos actually reverses in direction among the most liberal respondents (while the results for the black stereotype gap remain largely unchanged). ${ }^{12}$ That is, in these states liberals actually view Latinos as more "hard working" than whites. This result is presented in figure 4. Thus, to the extent that public opinion informs our expectations about the prev-

\footnotetext{
${ }^{12}$ We attempted to test this possibility by examining data from Florida in the NES, but the sample size was simply too small $(N=58)$. However, if we pool the samples from the three states with the largest Latino populations (California, Florida, and Texas), we are able to achieve a reasonable sample size.
} 


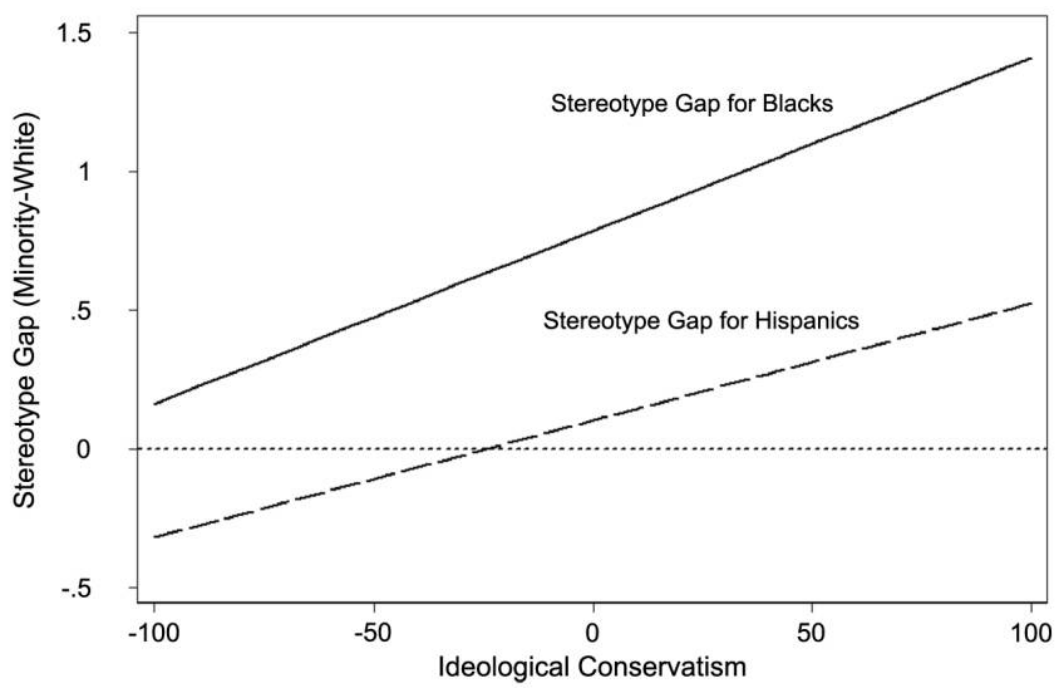

FIG. 4.-Average gap in perceived laziness of racial groups, by ideological identification of respondents (California, Florida, and Texas). Note: The vertical axis is the stereotype gap and is computed as the difference in the mean assessment of laziness for each pair of target groups (the mean score for blacks/Latinos minus the mean score for whites), where the laziness scale is coded as follows: $1=$ hardworking, $7=$ lazy. As scaled, the stereotype gap is a measure of the degree to which respondents view blacks (or Latinos) as lazier than whites. The measure of conservatism is computed as the feeling thermometer score for conservatives minus the score for liberals. The lines in the graph represent the predicted relationship between conservatism and the stereotype gap for each group, based on a bivariate regression that utilizes pooled data from the National Election Study (1996, 2000, 2004), with the sample restricted to respondents in California, Florida, and Texas. Each slope value is statistically significant $(P<.01)$.

alence of stereotypes in the most liberal regions in Florida, perhaps our empirical results for Florida are not so unusual after all.

A second possible explanation for this finding is that the early months of the spell may not fully reflect the exercise of discretion by welfare case managers and administrators. Based on field interviews that we conducted at all levels of the WT program, officials consistently reported that sanctions recorded in the first months of a spell often represent a form of "selfsanctioning" that is distinguishable from "true sanctioning" decisions made by case managers. In this scenario, an applicant with some alternative income options enters the official rolls, begins to receive assistance, but then does not return to the local provider after learning what will be required of them and how much cash aid they will receive in return. To the extent that this dynamic is most prevalent among whites, perhaps due to the greater availability of job market opportunities or assistance from family members, evidence of simple racial disparities may be damp- 
ened to some unknown degree during the early months of the TANF spell. If this is the case, the bias may be enough to push the sanction rate for whites above that of blacks and Latinos in areas where the three groups would otherwise be sanctioned at a more or less equal rate. ${ }^{13}$

By contrast, the results in table 1 offer strong support for the timecontingent disparity hypothesis, as revealed by the significant interactions between race/ethnicity of client and a simple counter variable (1-12) representing the month of the current TANF spell (Black $\times$ Month of Spell, Latino $\times$ Month of Spell). This interaction between race/ethnicity and month of spell is extremely robust across both specifications of our model and highlights the benefit of employing a longitudinal design, such as event history analysis, to study racial dynamics in TANF sanctioning.

We now turn our attention to the ideology-contingent disparity hypothesis, which predicts that sanctioning disparities are conditioned by the local political environment in which TANF is implemented. Our test of this hypothesis is based on the estimation of cross-level interactions between the racial/ethnic status of the client and our measures of local ideology (Local Conservatism in model 1 and Republican Vote Share in model 2). The results reported in table 1 strongly support our hypothesis. The effects of racial/ethnic status are indeed mediated by the ideological orientation of the local political environment. Not only is this the case regardless of which measure of local political ideology we use, we also find the mediating effect of ideological climate to be statistically significant for both black and Latino clients (although the effect is only weakly significant for Latino clients in model 1). For both groups (blacks and Latinos), movement from a liberal local environment to a conservative environment raises the probability of being sanctioned, not just in absolute terms but also relative to that of white non-Latinos. ${ }^{14}$ Given the complexity of the results presented in table 1 (due to interactions between race, time, and ideology), we present a series of graphical interpretations of these effects below in figures 5 and $6 .^{15}$

${ }^{13}$ This explanation might also explain why we see this pattern in Florida, but we fail to see it in the national data (as we report below). Florida's WT program is especially tough-not only does the WT program rely on the most severe type of sanction, but sanctions are enforced in Florida at a rate that is very high compared to other states. Thus, to the extent that this phenomenon of "self-sanctioning" is important, it is possible that we will only observe it (to a significant degree) in the most punitive states.

${ }^{14}$ One possible explanation for these results is that it is not ideology but rather the size of the minority population that mediates the effect of client race on sanctioning. To explore this possibility, we tested for interactions between racial/ethnic status of client and the black and Latino percentage of the county population (i.e., Black $x$ $\%$ Black and Latino $\times \%$ Latino). Neither term was statistically significant.

${ }^{15}$ All illustrations are based on the results from table 1, model 1. Similar patterns are observed when we use Republican Vote Share as our measure of local ideology. 

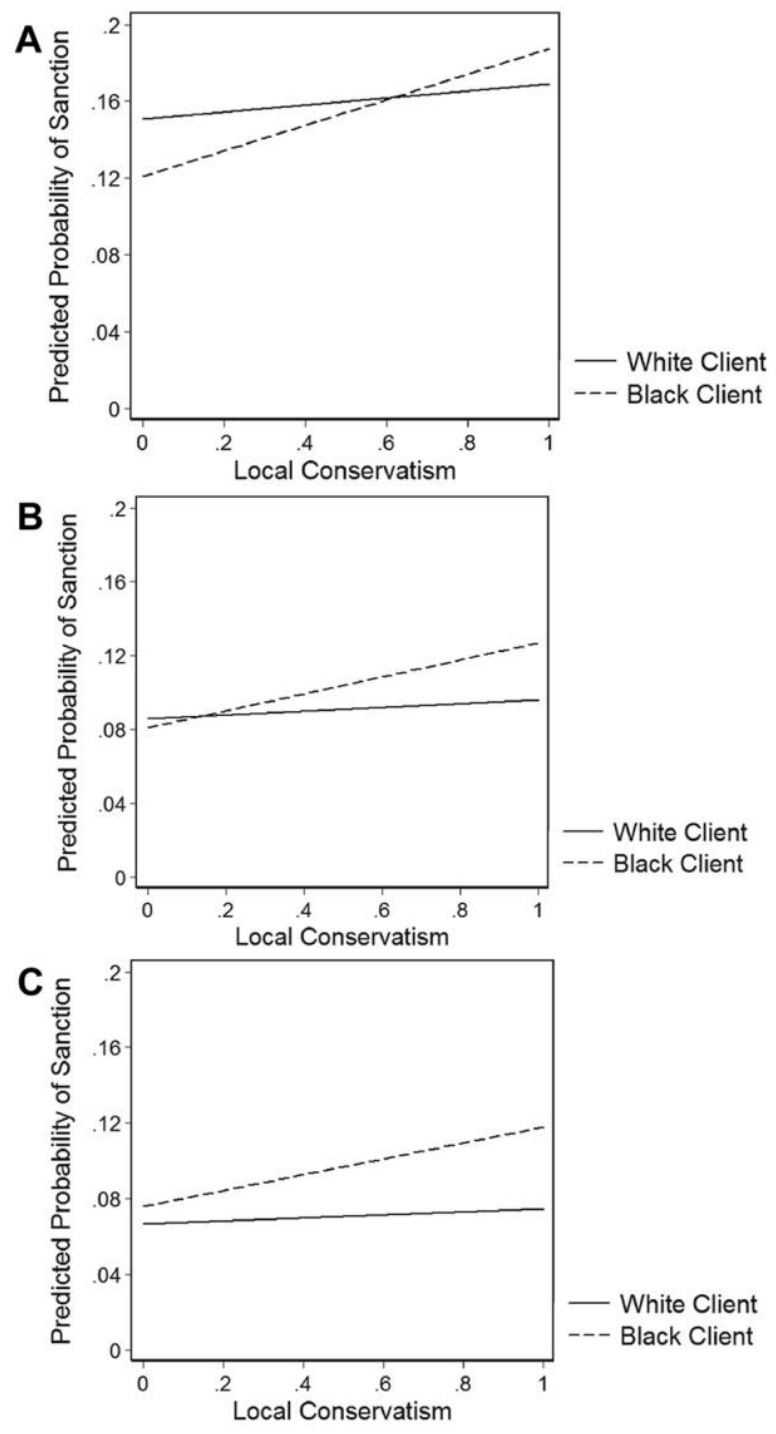

FIG. 5.-Predicted probability of being sanctioned for Florida TANF clients, by race, local political environment, and month of TANF spell. Note: A = month 3 of TANF spell, $\mathrm{B}=$ month 6 of TANF spell, $\mathrm{C}=$ month 9 of TANF spell. 

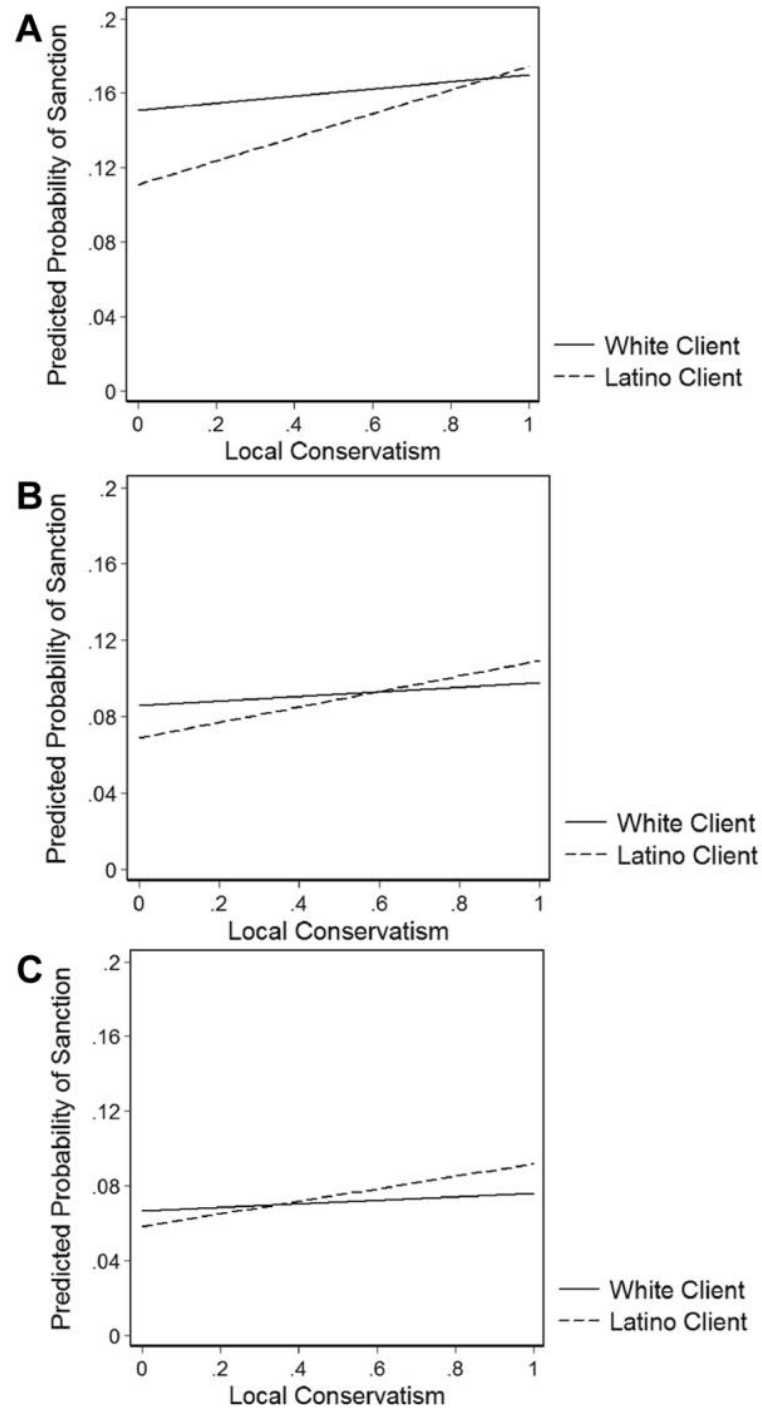

FIG. 6.-Predicted probability of being sanctioned for Florida TANF clients, by ethnicity, local political environment, and month of TANF spell. Note: A = month 3 of TANF spell, $\mathrm{B}=$ month 6 of TANF spell, $\mathrm{C}=$ month 9 of TANF spell. 
In figure 5 we present three graphs of the predicted probability of sanction for "typical" black and white clients, for months 3, 6, and 9 of the TANF spell. ${ }^{16}$ In each graph, the probability of sanction is plotted against our measure of local conservatism, thus allowing us to see how the risk of sanction varies across the entire range of local ideological context for both black and white clients. Figure 5 reveals several interesting features of the relationship between race and sanctioning. We can see that as we move from month 3 to month 9 of the TANF spell, the overall risk of sanction decreases for both blacks and whites (as reflected by the decreasing intercept values of the curves in the graphs). This is expected given the pattern of the baseline hazard reported in figure 1. However, this decrease in the rate of sanctioning is not consistent across racial groups. Moving from the third to the ninth month of the spell, whites display a reduction of approximately $56 \%$ in the predicted rate of sanction (for an ideologically moderate county), while the reduction for blacks is only about $33 \%$. This pattern of increasing black-white disparity across the duration of the spell is anticipated given the significant interaction between race and month of spell in our results.

Figure 5 also allows us to see how black-white disparities in sanctioning vary across the level of local conservatism. In all three graphs, we see that as we move from the most liberal to the most conservative environments, the probability of a black client being sanctioned, relative to that of a white client, increases. However, the pattern of racial disparities changes in a substantively meaningful way as the spell length increases. For clients in the third month of a TANF spell, we see that in liberal counties, white clients are significantly more likely to be sanctioned than black clients for a large majority of clients. Only in the most conservative counties does the predicted probability of sanction for blacks exceed that of whites. As the length of the spell grows longer, however, black clients become consistently more likely to experience a sanction than their white counterparts. Indeed, by the sixth month of the spell, in the most conservative counties the probability that a black client is sanctioned is predicted to be about $30 \%$ greater than that of a white client. By the ninth month of the spell, black clients are predicted to be sanctioned more than whites in every county and at a rate that is approximately $70 \%$ higher than that of whites in the most conservative counties.

Figure 6 consists of three identically constructed graphs comparing predicted probabilities for Latino clients and white clients. As can be seen,

\footnotetext{
${ }^{16}$ We define a "typical" client as a U.S.-born, 31-year-old single woman with two children (ages 5-12 years), fewer than 12 years of education, an average level of earned income, and who resides in an average county (reflecting mean values on all of the contextual variables).
} 
we observe several similarities between figures 5 and 6 in the pattern of racial/ethnic disparities. The risk of sanction for a Latino client, relative to that of a white client, increases as spell length increases and as one moves from a liberal to a conservative political climate. However, the magnitude of these changes in patterns of Latino-white disparities across these two contexts seems smaller than what we observe for black clients in figure 5. This is largely consistent with our theoretical assumptions regarding relatively smaller reputational gaps between Latinos and whites (see fig. 2) and in this sense provides additional support for our hypotheses. ${ }^{17}$

\section{Testing the Mediating Effect of Administrative Decentralization Using National TANF Data}

Thus far, our analysis of Florida TANF clients provides strong support for our racial classification model of policy choice. Yet, due to our examination of a single state, we are unable to test hypothesis 4 , which predicts that the effects of race/ethnicity will be stronger in states that rely on second-order devolution in TANF implementation. In addition, there may be reason to doubt the external validity of our findings from Florida due to our focus on sanctioning patterns in a single state. To address these issues, we now turn to an analysis of sanctioning that incorporates individual-level data from all 50 states, available from the Office of the Assistant Secretary for Planning and Evaluation (ASPE) in the U.S. Department of Health and Human Services.

The ASPE data consist of a series of state samples of TANF families collected by all 50 states from 1999 through 2005. These data are used by the federal government for annual state performance evaluations and consist of two types of samples-active cases and closed cases. In addition to variables measuring clients' personal characteristics, the closed case samples also provide information concerning the reason that the case was closed. Such reasons may include leaving welfare for employment, getting married, and being sanctioned, among others. We therefore rely on these data from the closed case samples to construct our dependent variable. Given that we limit the analysis to closed cases, we expect to find some differences compared to the Florida sample that includes open as well as

\footnotetext{
${ }^{17}$ We have replicated the analyses presented in table 1 using two alternative estimation techniques used to analyze multilevel data-logistic regression with clustered standard errors (by county), and a two-stage regression method. These results confirm the interaction between Black Client and Local Conservatism, but unlike the HGLM results, we also find a significant interaction between Latino Client and Local Conservatism. We do not present these results in this article, as we have the most confidence in the HGLM results. However, we do provide these results for interested readers in the online appendix.
} 
closed cases. Yet, there is reason to think that sanction exits in this population are affected as we have hypothesized. For our analysis, we pool all closed case samples for the entire 1999-2005 period. We restrict our analysis to all adult TANF recipients who were identified as the head of the household by the state. Using this definition, and accounting for some missing data, our final data set consists of approximately 195,000 TANF adults residing in nearly 2,700 different counties. Unfortunately, these data are purely cross-sectional in nature, and therefore we cannot exactly replicate our analysis of sanctioning in Florida using nationally representative data. However, these data do allow us to provide a strong test of the effects of decentralized administration, as well as a limited replication of our tests of the simple disparity hypothesis and the ideology-contingent disparity hypothesis.

Our dependent variable is Sanction Exit $_{j k}$ - a dichotomous variable that indicates whether or not client $j$, residing in county $k$, left TANF due to a sanction. We model the probability of a sanction exit as a function of both individual-level and contextual (county) variables. Therefore, we estimate a (cross-sectional) multilevel model, using a logit link (as our dependent variable is dichotomous). The individual-level (level 1) model is represented below in equation (6).

$$
\begin{aligned}
& \text { Sanction Exit } \text { Ek }_{j k}=\beta_{0 k}+\beta_{1 k} \text { Black }_{j}+\beta_{2 k} \text { Latino }_{j}+\beta_{3 k} \text { No. Children (2) } \\
& +\beta_{4 k} \text { No. Children (3 or more) } \\
& \left.+\beta_{5 k} \text { Age of Youngest Child (3 mos. }-2 \text { yrs. }\right)_{j} \\
& +\beta_{6 k} \text { Age of Youngest Child }(3-4 \mathrm{yrs} .)_{j} \\
& +\beta_{7 k} \text { Age of Youngest Child }(5-11 \mathrm{yrs})_{j} \\
& \left.+\beta_{8 k} \text { Age of Youngest Child (12 or more }\right)_{j} \\
& +\beta_{9 k} \text { Education }(12 \mathrm{yrs} .)_{j}+\beta_{10 k} \text { Education }(>12 \mathrm{yrs} .)_{j} \\
& +\beta_{11 k} \text { Male }_{j}+\beta_{12 k} \text { Citizen }_{j}+\beta_{13 k} \text { Age }_{j} \\
& +\beta_{14 k} \text { Single Parent }_{j}+\beta_{15 k} \text { Earned Income }_{j} \\
& +\beta_{16 k} \text { Public Housing }_{j}+\beta_{17 k} \text { OASDI }_{j}+\beta_{18 k} \text { SSI }_{j} \\
& +\beta_{19 k} \text { Year } 2000_{j}+\beta_{20 k} \text { Year } 2001_{j} \\
& +\beta_{21 k} \text { Year } 2002_{j}+\beta_{22 k} \text { Year } 2003_{j} \\
& +\beta_{23 k} \text { Year } 2004_{j}+\beta_{24} \text { Year2005 }_{j}
\end{aligned}
$$


The county-level (level 2) model is represented below in equations (7)(10).

$$
\begin{gathered}
\beta_{0 k}=\gamma_{00}+\gamma_{01} \text { Republican Vote Share }_{k}+\gamma_{02} \text { OBlack }_{k} \\
+\gamma_{03} \% \text { Latino }_{k}+\gamma_{04} \text { Per Capita Income }_{k} \\
+\gamma_{05} \text { Unemployment Rate }_{k}+\epsilon_{0 k}, \\
\beta_{1 k}=\gamma_{10}+\gamma_{11} \text { Republican Vote Share } \\
k
\end{gathered}
$$

\section{Level 1 Hypotheses}

To test the simple disparity hypothesis, we once again classify clients as black, Latino, and white (non-Latino) and include the dichotomous variables Black and Latino. We expect that the coefficient values will be positive for each of these variables $\left(\beta_{1}, \beta_{2}>0\right)$ and the coefficient for Black will be larger than the coefficient for Latino $\left(\beta_{1}>\beta_{2}\right)$.

We also include a number of other variables to control for variation in clients' individual characteristics. Many of these variables are identical (or very similar) to the variables we included in our analysis of Florida TANF clients, so we do not provide a detailed description of justification for their inclusion. ${ }^{18}$ These include variables measuring the client's gender (Male), citizenship status (Citizen), age (Age), age of the youngest child in the TANF family, the number of children in the TANF family, the client's marital status (Single Parent), and two indicators of human capital (Earned Income and Education). We also take advantage of information in the national TANF data set and include three additional indicators of client hardship. These include two dichotomous variables indicating whether a former TANF client received disability benefits through the Social Security or Supplemental Security Income programs (OASDI, SSI) and whether a TANF family lived in public housing (Public Housing). Finally, we include a series of dummy variables for the year that the TANF sample was collected.

\footnotetext{
${ }^{18}$ Details for these variables, including measurement, data sources, and descriptive statistics, are provided in the online appendix.
} 


\section{Level 2 Hypotheses}

As in our analysis of Florida TANF clients, we model the intercept of equation (6) $\left(\beta_{0 k}\right)$ as a function of local political, economic, and social conditions. To measure the local political context in the national data, we rely on the Republican share of the two-party presidential vote, averaged over the past three presidential elections (Republican Vote Share). We also control for the local racial context by including the percentage of the county population that is black and Latino, respectively (\% Black, \% Latino). To capture the effects of local economic conditions, we include the county unemployment rate (Unemployment Rate) and per capita income (Per Capita Income). Finally, we test the ideology-contingent disparity hypothesis by including Republican Vote Share as a predictor for the effects of Black $\left(\beta_{1 k}\right)$ and Latino $\left(\beta_{2 k}\right)$, as reflected in equations (8) and (9). As we expect racial disparities to be larger in conservative counties, we expect $\gamma_{11}$ and $\gamma_{21}$ to be positive.

To test hypothesis 4 (the decentralization-contingent disparity hypothesis), we estimate our model separately for the 36 state governments that administer TANF directly and the 14 states that have devolved significant authority in TANF implementation to local governments or regional workforce boards-that is, states with second-order devolution (Gainsborough 2003).$^{19}$ For reasons outlined above, we expect that the effects of racial classification may be enhanced in SOD states, and, as a result, racial classification may more likely to result in racial disparities in sanctioning outcomes.

\section{Results}

The results of our analyses are presented in table 2. Once again, we find that sanctions are significantly related to clients' individual traits, within both SOD and centralized (i.e., non-SOD) states. The probability of being sanctioned is higher for clients who are younger, have older children (SOD states only), are citizens, and possess less human capital (as measured by education level and earned income). These results are generally consistent across SOD and non-SOD states, and they are generally consistent with our results from Florida. However, the effects of several variables diverge from our initial findings from Florida. For example, gender plays no role in sanctioning in SOD states, and in centralized states it is women, as opposed to men, who are more likely to be sanctioned. In addition, while being a single parent has no effect on sanctioning in SOD states, we find

\footnotetext{
${ }^{19}$ These 14 states include Arkansas, California, Colorado, Florida, Maryland, Michigan, Minnesota, New York, North Carolina, Ohio, Tennessee, Texas, Utah, and Wisconsin.
} 
that single parents are more likely (rather than less likely) to be sanctioned in centralized states. Finally, we see that clients who receive disability benefits or live in public housing are significantly more likely to have left TANF due to a sanction, perhaps reflecting significant employment barriers among these clients.

Moving to our contextual variables, sanction exits are significantly more likely to occur in counties with larger black populations, as well as in counties with larger Latino populations (in centralized states). We find weaker effects for the local economic context, although the unemployment rate is positively related to sanction exits in centralized states.

We now turn our attention to the tests of the simple disparity and ideology-contingent disparity hypotheses and the relative performance of these hypotheses across SOD and centralized administrative environments. As in our initial analysis of TANF sanctioning among Florida clients, we centered Republican Vote Share by subtracting its mean so that the coefficients for Black and Latino in table 2 reflect the effects of race and ethnicity in a typical (i.e., politically moderate) county. As we saw in Florida, the results for the national data find the effects of race and ethnicity to be insignificant in such a county, in both SOD and nonSOD states. However, this does not mean to suggest that racial disparities are entirely absent, as evidenced by the results of our test of the ideologycontingent hypothesis. As in our Florida analysis, our test of this hypothesis is based on the estimation of cross-level interactions between the racial/ethnic status of the client and our measure of local ideology (Republican Vote Share). Among black clients, the effect of racial status is indeed mediated by the ideological orientation of the local political environment. And consistent with theoretical expectations concerning the nature of the implementation environment, the effect is limited to SOD states. However, we find no interaction between ethnicity (Latino) and the local political environment in either sample of states.

In figure 7, we provide a graphical illustration of the relationship between race and sanctioning in SOD states that offers a clearer understanding of exactly how this relationship is mediated by local ideology. Figure 7 presents the predicted probability of a sanction exit for a typical client by the race of the client and the local political environment. ${ }^{20}$ As we saw in Florida (see fig. 5), black clients and white clients are predicted to be sanctioned at more or less equivalent rates in liberal and moderate counties. But as we move to the right along the horizontal axis, we see

\footnotetext{
${ }^{20}$ We define a "typical" client as a U.S.-born, 31-year-old single woman with two children (ages 5-12 years), fewer than 12 years of education, and an average level of earned income, who resides in an average county (reflecting mean values on all of the contextual variables).
} 


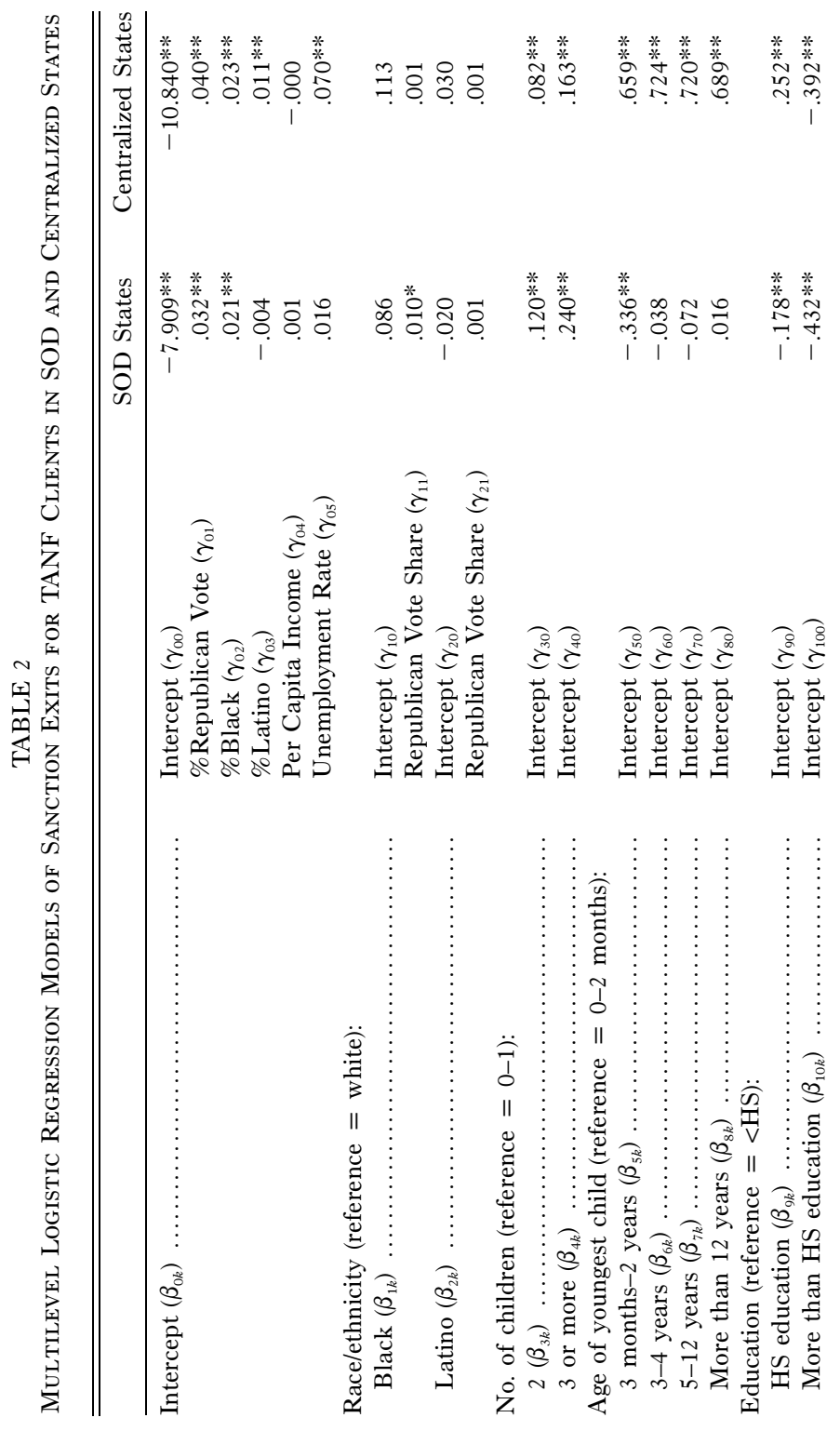




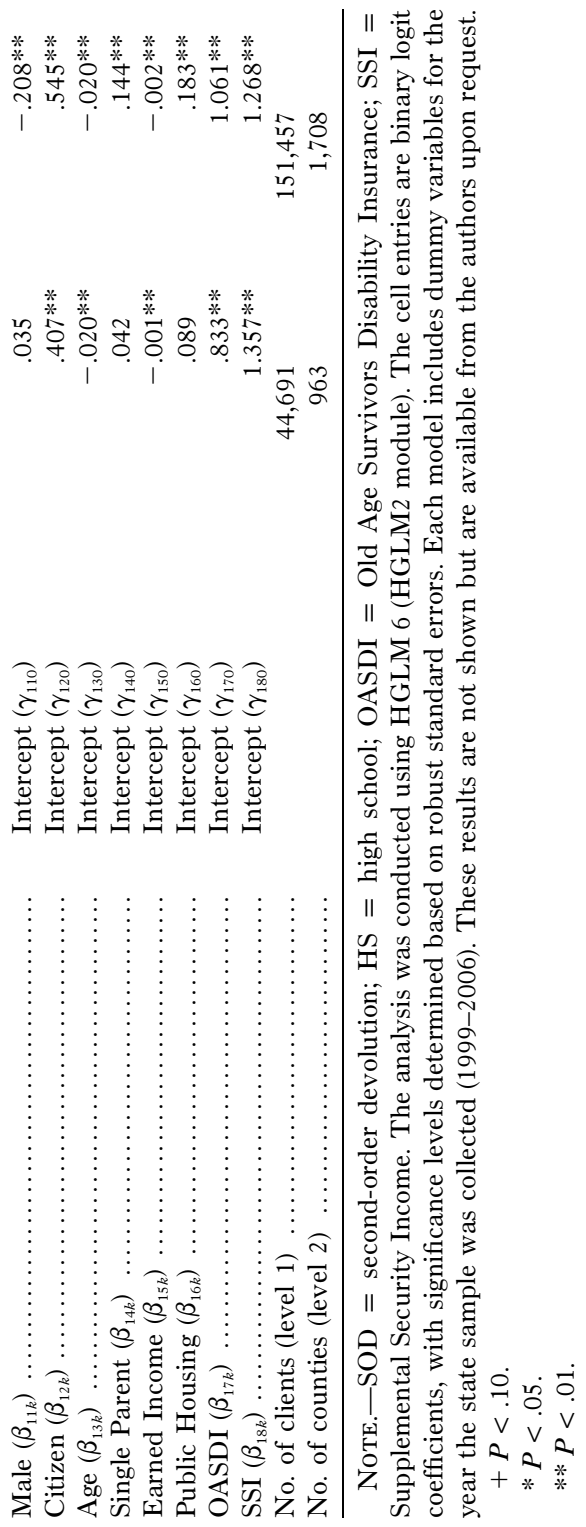




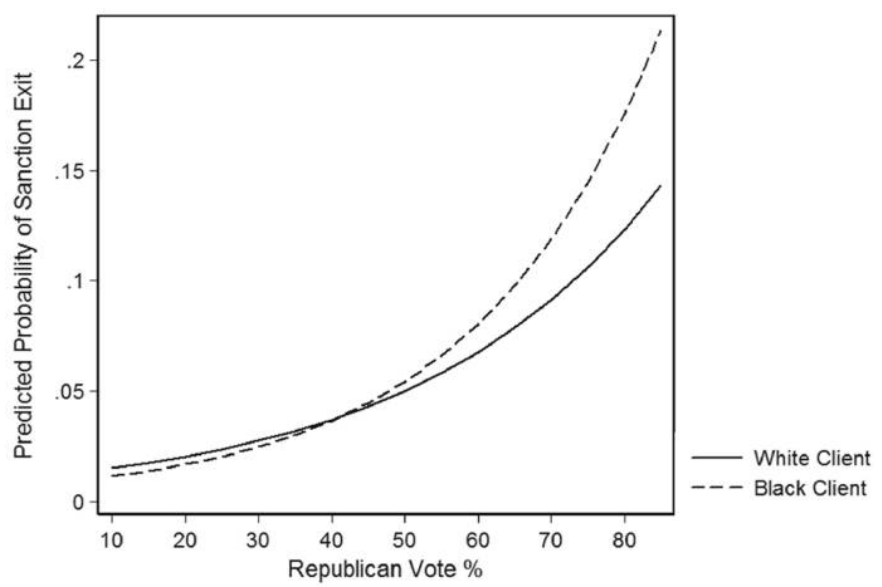

FIG. 7.-Predicted probability of sanction in second-order devolution states, by race of client and local political environment. Note: Predicted probabilities were calculated based on the results presented in table 2 for the second-order devolution sample of states.

that racial disparities quickly emerge in the anticipated direction. Indeed, in the most conservative counties the predicted probability of a sanction exit is approximately $70 \%$ greater for blacks than it is for whites. Given the consistency of this finding across two very different data sets and research designs, this result provides important confirmation of the mediating effects of local ideology and administrative decentralization, and ultimately, our racial classification model of policy choice.

\section{CONCLUSION}

Poverty governance in the United States has been redefined over the past several decades to emphasize decentralized systems of disciplinary engagement with the poor. More muscular approaches to paternalism and correctional control have intersected with neoliberal reforms emphasizing devolution, privatization, and quasi-market performance pressures. As Loïc Wacquant (2009) rightly argues, penal logics and policing (in a broad sense) have been extended from the field of criminal justice to the operations of welfare programs. As a facet of poverty governance, the state's carceral "right hand" has not only risen in relative importance, it has provided a new logic for the state's "left hand" of social welfare provision. This new system has profound implications for status, power, and marginality among the mostly female and disproportionately nonwhite people enrolled in welfare programs today. Like their predominantly male counterparts under correctional control, poor women on welfare are subject 
to a disciplinary regime where penalties for noncompliance loom large and resources to counter social and economic marginality remain difficult to access.

Our study has yielded substantial evidence for Wacquant's core claims regarding the disciplinary turn in welfare provision and the centrality of race for contemporary poverty governance. Earlier research has demonstrated that state policy choices under welfare reform have produced a tight triadic relationship linking higher black population rates, more disciplinary and localized TANF regimes, and more aggressive correctional control (Soule and Zylan 1997; Soss et al. 2001; Soss et al. 2008; Waquant 2009). In the present study, we have shifted the focus from state policy choices to local implementation efforts. The evidence presented in this article has underscored that racial classifications continue to shape the operations of poverty governance at all levels of the U.S. system.

In this respect, our study aligns closely with Wacquant's analysis of contemporary poverty governance. Our approach to analysis, however, has also yielded important differences. Where Wacquant offers a sweeping historical interpretation of national developments, we pay closer attention to how policies and practices vary across jurisdictions, institutions, and circumstances. The disciplinary turn has not unfolded in a uniform manner across the nation, and this observation is central to understanding the racial basis of disciplinary governance. American federalism functions today as a powerful mechanism for the production of racial disparities. Under first-order devolution, several studies have shown that states with larger black populations have adopted the most disciplinary polices and, as a result, African-Americans have been subjected to the most disciplinary regimes. Similarly, our results show that second-order devolution has paved the way for a complex interplay of political conservatism and racial bias in welfare sanctioning-a dynamic that does not appear in states that have retained more centralized control. These and related patterns underscore the contingency of racial dynamics in poverty governance today and highlight how institutional structures play a critical mediating role.

Our study also differs from past analyses, including Waquant's, in that it offers a more subtle and contingent account of how race matters for the implementation of punitive policy tools within the new system of poverty governance. Unlike broad models of racial control and prejudice, the RCM emphasizes, and our empirical results confirm, that racial disparities are far more likely to arise in some circumstances than in others. As we have seen, racial disparities in welfare sanctioning have been highly contingent on the structure of governing arrangements, the character of local political environments, the presence of stereotype-consistent markers, and relative differences in group reputations. Indeed, under some 
conditions specified here, black and Latino welfare recipients emerge as no more likely, or even less likely, than their white counterparts to be sanctioned. Minority disadvantage arises in the disciplinary process primarily as a function of community and client characteristics that heighten the degree of contrast associated with racial-group reputations, including stereotypes associated with nonwhite women taking welfare for extended periods.

In the welfare context, long-term program usage is a discrediting mark that can associate a recipient with dependency, irresponsibility, and lack of effort. The toll imposed by this discrediting mark, however, turns out to vary across racial groups in our analysis. As TANF participation spells grow longer, it is minority, and especially black, clients who become increasingly subject to penalties. This result is consistent not only with the $\mathrm{RCM}$ but also with a line of experimental research suggesting that welfare reliance has different meanings when attached to blacks and whites (Gilens 1999) and that stigmatizing, stereotype-consistent cues interact with racial status to disadvantage blacks relative to whites (Valentino et al. 2002; Pager 2003). In the Florida WT program, black-white disparities increase over the course of the participation spell, suggesting that blacks are disproportionately tainted by-and ultimately taxed for-the stigma of long-term program usage.

Likewise, we find that racial disparities in sanctioning depend significantly on local context. Larger disparities emerge in more ideologically conservative jurisdictions and within states that delegate significant discretion to local decision makers through second-order devolution. Our interpretation of these results flows, once again, from the basic premises of the RCM. According to this model, racial disparities in policy treatment should emerge to a greater degree in those times and places where officials are more likely to hold stereotypes that distinguish racial groups in policyrelevant ways, and where such officials are afforded a greater opportunity to translate those beliefs into policy outcomes.

These findings have immediate relevance for public policy, as well as broader implications for the history of welfare provision. Our results complement other studies of welfare sanctioning that find that frontline workers exercise considerable discretion in the implementation of sanctions and often do so in a way that is inconsistent with policy intent (Lens 2006). Numerous studies have also found that sanctions do little to improve the lives of welfare families and may actually cause additional stress and disadvantage (Pavetti et al. 2003; Meyers et al. 2006). Our results add additional justification to arguments that policy makers should consider redesigning sanctions as a policy tool, or at the very least consider adding some safeguards to help insure that sanctions are administered in a nondiscriminatory and less arbitrary fashion. Examples of such mea- 
sures might include the use of explicit performance measures that monitor the racial distribution of sanctions (Gooden 2003) and efforts to promote awareness of and participation in the sanction appeal process (Lens 2008).

Finally, we end with a broader point about the history of welfare provision. Scholars have often suggested that welfare has followed a "vicious cycle" in which social inequalities have shaped policy choices that, in turn, have recreated social inequalities (Lieberman 1998; Mettler 1998; Schram 2006). Negative images of target groups guide policy design and implementation, and policy designs are then implemented in ways that reinforce negative group outcomes and reputations (Schneider and Ingram 1993; Schram 1995, 2005). The analysis presented here raises the prospect that such dynamics may be at work today in contemporary welfare reform. Racial politics contributed greatly to federal welfare reform in 1996 (Gilens 1999; Soss et al., in press), which devolved substantial policy authority to the states. State choices regarding TANF program design were then significantly influenced by racial composition and resulted in black families being disproportionately concentrated in the policy regimes with the toughest rules and sanctions (Soss et al. 2001; Fellowes and Rowe 2004) and the most decentralized administrative systems (Soss et al. 2008). In this article, we show how these dynamics converge and repeat at the local level. The decentralized administrative structure possible under welfare reform facilitates the ideologically specific production of racial disparities in sanction implementation. As a result, today, as in the past, public aid for poor women and children remains entangled with the complex interplay of race, politics, and local policy control.

\section{REFERENCES}

Abramovitz, Mimi. 1988. Regulating the Lives of Women: Welfare Policy from Colonial Times to the Present. Boston: South End Press.

$\rightarrow$ Adkisson, Richard V. 1998. "Multi-Level Administrative Structure and the Distribution of Social Service Expenditures: A Nebraska Example.” Social Science Journal 35: 303-18.

$\rightarrow$ Barber, Jennifer S., Susan A. Murphy, William G. Axinn, and Jerry Maples. 2000. "Discrete-Time Multilevel Hazard Analysis." Sociological Methodology 30:201-35.

$\rightarrow$ Beck, Nathaniel, Jonathan Katz, and Richard Tucker. 1998. "Taking Time Seriously: Time-Series Cross-Section Analysis with a Binary Dependent Variable." American Journal of Political Science 42:1260-88.

$\rightarrow$ Borjas, George J., and Glenn T. Sueyoshi. 1994. "A Two-Stage Estimator for Probit Models with Structural Group Effects." Journal of Econometrics 64:165-82.

Botsko, Christopher, Kathleen Snyder, and Jacob Leos-Urbel. 2001. Recent Changes in Florida Welfare and Work, Child Care, and Child Welfare Systems. Washington, D.C.: Urban Institute.

Brown, Wendy. 2003. "Neo-Liberalism and the End of Liberal Democracy." Theory and Event 7. http://muse.jhu.edu/journals/theory_and_event/.

$\rightarrow$ - 2006. "American Nightmare: Neoliberalism, Neoconservatism, and Dedemocratization." Political Theory 34:690-714. 
Collins, Jane L., and Victoria Mayer. 2010. Both Hands Tied: Welfare Reform and the Race to the Bottom in the Low-Wage Labor Market. Chicago: University of Chicago Press.

Collins, Patricia Hill. 2005. Black Sexual Politics: African Americans, Gender, and the New Racism. New York: Routledge.

Cook, Fay Lomax, and Edith J. Barrett. 1992. Support for the American Welfare State: The Views of Congress and the Public. New York: Columbia University Press.

$\rightarrow$ Devine, Patricia G., and Sarah M. Baker. 1991. "Measurement of Racial Stereotype Subtyping." Personality and Social Psychology Bulletin 17:44-50.

$\rightarrow$ Domke, David. 2001. "Racial Cues and Political Ideology." Communication Research 28:772-801.

$\rightarrow$ Dyck, Joshua J., and Laura S. Hussey. 2008. "The End of Welfare as We Know It? Durable Attitudes in a Changing Information Environment." Public Opinion Quarterly 72:589-618.

$\rightarrow$ Eberhardt, Jennifer L., Paul G. Davies, Valerie J. Purdie-Vaughns, and Sheri Lynn Johnson. 2006. "Looking Deathworthy: Perceived Stereotypicality of Black Defendants Predicts Capital Sentencing Outcomes." Psychological Science 17:383-86.

Federico, Christopher M., and Jim Sidanius. 2002. "Sophistication and the Antecedents of Whites' Racial Policy Attitudes: Racism, Ideology, and Affirmative Action in America." Public Opinion Quarterly 66:145-76.

$\rightarrow$ Fellowes, Matthew, and Gretchen Rowe. 2004. "Politics and the New American Welfare States." American Journal of Political Science 48:362-73.

Fording, Richard C. 2003. "Laboratories of Democracy' or Symbolic Politics? The Racial Origins of Welfare Reform." In Race and the Politics of Welfare Reform, ed. Sanford F. Schram, Joe Soss, and Richard C. Fording. Ann Arbor: University of Michigan Press.

$\rightarrow$ Fording, Richard C., Joe Soss, and Sanford F. Schram. 2007. "Devolution, Discretion and the Impact of Local Political Values on TANF Sanctioning." Social Service Review 81:285-316.

Fox, Cybelle. 2004. "The Changing Color of Welfare? How Whites' Attitudes toward Latinos Influence Support for Welfare.” American Journal of Sociology 110:580-625.

$\rightarrow$ Gainsborough, Juliet F. 2003. "To Devolve or Not to Devolve? Welfare Reform in the States." Policy Studies Journal 31:603-23.

Gilens, Martin. 1999. Why Americans Hate Welfare: Race, Media, and the Politics of Antipoverty Policy. Chicago: University of Chicago Press.

$\rightarrow$ Glaser, James M. 1994. "Back to the Black Belt: Racial Environment and White Racial Attitudes in the South." Journal of Politics 56:21-41.

Gooden, Susan T. 2003. "Contemporary Approaches to Enduring Challenges: Using Performance Measurement to Promote Racial Equality under TANF." Pp. 254-78 in Race and the Politics of Welfare Reform, ed. Sanford F. Schram, Joe Soss, and Richard C. Fording. Ann Arbor: University of Michigan Press.

Gordon, Linda. 1994. Pitied but Not Entitled: Single Mothers and the History of Welfare, 1890-1935. New York: Free Press.

Hancock, Ange-Marie. 2004. The Politics of Disgust. New York: New York University Press.

—. 2007. "When Multiplication Doesn't Equal Quick Addition: Examining Intersectionality as a Research Paradigm." Perspectives on Politics 5:63-79.

Haney, Lynn. 2004. "Introduction: Gender, Welfare, and States of Punishment." Social Politics 11:333-62.

Harvey, David. 2005. A Brief History of Neoliberalism. New York: Oxford University Press.

$\rightarrow$ Hasenfeld, Yeheskel. 1987. "Power in Social Work Practice." Social Service Review 61:469-83.

$\rightarrow$ Hasenfeld, Yeheskel, Toorjo Ghose, and Kadyce Larson. 2004. "The Logic of Sanc- 


\section{American Journal of Sociology}

tioning Welfare Recipients: An Empirical Assessment.” Social Service Review 78: 304-19.

Hays, Sharon. 2003. Flat Broke with Children: Women in the Age of Welfare Reform. Oxford: Oxford University Press.

Hero, Rodney. 1998. Faces of Inequality: Social Diversity in American Politics. New York: Oxford University Press.

$\rightarrow$ Jacobs, David, and Jason T. Carmichael. 2002. "The Political Sociology of the Death Penalty: A Pooled Time-Series Analysis." American Sociological Review 67:109-31.

$\rightarrow$ Johnson, Monica Kirkpatrick, and Margaret Mooney Marini. 1998. "Bridging the Racial Divide in the United States: The Effect of Gender." Social Psychology Quarterly 61:247-58.

Jordan-Zachery, Julia. 2008. Black Women, Cultural Images and Social Policy. New York: Routledge.

$\rightarrow$ Kalil, Ariel, Kristin S. Seefeldt, and Hui-chen Wang. 2002. "Sanctions and Material Hardship under TANF." Social Service Review 76:643-62.

Katz, Michael B. 1996. In the Shadow of the Poorhouse: A Social History of Welfare in America. Expanded ed. New York: Basic Books.

Katznelson, Ira. 2005. When Affirmative Action Was White: An Untold History of Racial Inequality in Twentieth-Century America. New York: Norton.

Keech, William R. 1981. The Impact of Negro Voting: The Role of the Vote, the Quest for Equality. Westport, Conn.: Greenwood.

$\rightarrow$ Keiser, Lael R., Peter Meuser, and Seung-Whan Choi. 2004. "Race, Bureaucratic Discretion, and the Implementation of Welfare Reform." Journal of Political Science 48:314-27.

Kettl, Donald F. 2002. The Transformation of Governance: Public Administration for Twenty-first Century America. Baltimore, Md.: Johns Hopkins University Press.

Key, V. O., Jr. 1949. Southern Politics in State and Nation. New York: Knopf.

Koralek, Robin. 2000. "South Carolina Family Independence Program Process Evaluation." Prepared for South Carolina Department of Social Services. Urban Institute, Washington, D.C.

$\rightarrow$ Korteweg, Anna. 2003. "Welfare Reform and the Subject of the Working Mother: 'Get a Job, a Better Job, Then a Career."” Theory and Society 32:445-80.

$\rightarrow$ Krinsky, Jonathan. 2007. "The Urban Politics of Workfare." Urban Affairs Review 42: 771-98.

Lasswell, Harold. 1936. Politics: Who Gets, What, When, How. New York: McGrawHill.

$\rightarrow$ Lens, Vicki. 2006. "Examining the Administration of Work Sanctions on the Front Lines of the Welfare System." Social Science Quarterly 87:573-90.

$\rightarrow-$. 2008. "Welfare and Work Sanctions: Examining Discretion on the Frontlines." Social Service Review 82:197-222.

Lieberman, Robert. 1998. Shifting the Color Line: Race and the American Welfare State. Cambridge, Mass.: Harvard University Press.

Mancuso, David, and Vanessa L. Lindler. 2001. "Examining the Circumstances of Welfare Leavers and Sanctioned Families in Sonoma County [CA]: Final Report." SPHERE Institute, Burlingame, Calif.

$\rightarrow$ Maynard-Moody, Steven, and Michael C. Musheno. 2000. "State Agent or Citizen Agent: Two Narratives of Discretion." Journal of Public Administration Research and Theory 10:329-58.

2003. Cops, Teachers, Counselors: Stories from the Front Lines of Public Service. Ann Arbor: University of Michigan Press.

$\rightarrow$ McCall, Leslie. 2005. "The Complexity of Intersectionality." Signs: Journal of Women in Culture and Society 30:1771-1800.

Mead, Lawrence M., ed. 1997. The New Paternalism: Supervisory Approaches to Poverty. Washington, D.C.: Brookings Institution Press. 
- 1998. "Telling the Poor What to Do." Public Interest 132:97-112.

2004. Government Matters: Welfare Reform in Wisconsin. Princeton, N.J.: Princeton University Press.

- 2005. "Welfare Reform and Citizenship." Pp. 172-99 in Welfare Reform and Political Theory, edited by Lawrence M. Mead and Christopher Beem. New York: Russel Sage Foundation.

Meier, Kenneth J. 1993. Politics and the Bureaucracy. Pacific Grove, Calif.: Brooks/ Cole.

Mendelberg, Tali. 2001. The Race Card: Campaign Strategy, Implicit Messages, and the Norm of Equality. Princeton, N.J.: Princeton University Press.

Mettler, Suzanne. 1998. Dividing Citizens: Gender and Federalism in New Deal Public Policy. Ithaca, N.Y.: Cornell University Press.

Meyers, Marcia K., Shannon Harper, Marieka Klawitter, and Taryn Lindhorst. 2006. "Review of Research on TANF Sanctions." Report. West Coast Poverty Center, University of Washington, Seattle.

Miller, Warren E. 1999. "Temporal Order and Causal Inference." Political Analysis 8: 119-46.

Mink, Gwendolyn. 2002. Welfare's End. Rev. ed. Ithaca, N.Y.: Cornell University Press.

Mittelstadt, Jennifer. 2005. From Welfare to Workfare: The Unintended Consequences of Liberal Reform, 1945-1965. Chapel Hill: University of North Carolina Press.

Nathan, Richard P. 1996. "The Devolution Revolution: An Overview." Pp. 5-13 in Rockefeller Institute Bulletin. New York: Rockefeller Institute of Government, State University of New York.

Nelson, Barbara J. 1990. "The Origins of the Two-Channel Welfare State: Workmen's Compensation and Mother's Aid." In Women, the State, and Welfare, ed. Linda Gordon. Madison: University of Wisconsin Press.

Neubeck, Kenneth, and Noel Cazenave. 2001. Welfare Racism: Playing the Race Card against America's Poor. New York: Routledge.

$\rightarrow$ Oliver, J. Eric, and Tali Mendelberg. 2000. "Reconsidering the Environmental Determinants of White Racial Attitudes." American Journal of Political Science 44:57489.

$\rightarrow$ Pager, Devah. 2003. "The Mark of a Criminal Record." American Journal of Sociology 108:937-75.

Pavetti, LaDonna, Michelle K. Derr, and Heather Hesketh. 2003. "Review of Sanction Policies and Research Studies: Final Literature Review.” Report prepared for Office of the Assistant Secretary for Planning and Evaluation, Mathematica Policy Research, Washington, D.C.

Pavetti, LaDonna A., Kathleen A. Maloy, Peter Shin, Julie Darnell, and Lea ScarpullaNolan. 1998. "A Description and Assessment of State Approaches to Diversion Programs and Activities under Welfare Reform." Report prepared for Office of the Assistant Secretary for Planning and Evaluation, Mathematica Policy Research, Washington, D.C.

$\rightarrow$ Peck, Jamie, and Adam Tickell. 2002. "Neoliberalizing Space." Antipode 34:380-404.

Peffley, Mark, Jon Hurwitz, and Paul Sniderman. 1997. "Racial Stereotypes and Whites' Political Views of Blacks in the Context of Welfare and Crime." American Journal of Political Science 41:30-60.

Piven, Frances Fox, and Richard A. Cloward. 1971. Regulating the Poor: The Public Functions of Welfare. New York: Vintage.

Prottas, Jeffrey M. 1979. People-Processing: The Street-Level Bureaucrat in Public Service Bureaucracies. Lexington, Mass.: Lexington Books.

Quadagno, Jill. 1994. The Color of Welfare: How Racism Undermined the War on Poverty. New York: Oxford University Press.

$\rightarrow$ Quillian, Lincoln. 2008. "Does Unconscious Racism Exist?" Social Psychology Quarterly 71:6-11. 


\section{American Journal of Sociology}

Rector, Robert E., and Sarah E. Youssef. 1999. "The Determinants of Welfare Caseload Decline." Report no. 99-04. Heritage Foundation, Washington, D.C.

$\rightarrow$ Richards, Zoe, and Miles Hewstone. 2001. "Subtyping and Subgrouping: Processes for the Prevention and Promotion of Stereotype Change." Personality and Social Psychology Review 5:52-73.

Ridzi, Frank. 2004. "Making TANF Work: Organizational Restructuring, Staff BuyIn, and Performance Monitoring in Local Implementation." Journal of Sociology and Social Welfare 31:27-48.

- 2009. Selling Welfare Reform: Work-First and the New Common Sense of Employment. New York: New York University Press.

$\rightarrow$ Schneider, Anne, and Helen Ingram. 1993. "Social Construction of Target Populations: Implications for Politics and Policy." American Political Science Review 87:334-47.

- 1997. Policy Design for Democracy. Lawrence: University Press of Kansas.

Schram, Sanford F. 1995. Words of Welfare: The Poverty of Social Science and the Social Science of Poverty. Minneapolis: University of Minnesota Press.

$\rightarrow-$ 2000. "In the Clinic: The Medicalization of Welfare."Social Text 18:81-107.

$\rightarrow$ - 2005. "Contextualizing Racial Disparities in American Welfare Reform: Toward a New Poverty Research." Perspectives on Politics 3:253-68.

- 2006. Welfare Discipline: Discourse, Governance and Globalization. Philadelphia: Temple University Press.

$\rightarrow$ Schram, Sanford F., Joe Soss, Richard C. Fording, and Linda Houser. 2009. "Deciding to Discipline: Race, Choice, and Punishment at the Frontlines of Welfare Reform." American Sociological Review 74:398-422.

Schuman, Howard, Charlotte Steeh, Lawrence Bobo, and Maria Krysan. 1997. Racial Attitudes in America: Trends and Interpretations. Rev. ed. Cambridge, Mass.: Harvard University Press.

Sears, David O., Jim Sidanius, and Lawrence Bobo, eds. 2000. Racialized Politics: The Debate about Racism in America. Chicago: University of Chicago Press.

$\rightarrow$ Somers, Margaret R., and Fred Block. 2005. "From Poverty to Perversity: Ideas, Markets, and Institutions over 200 Years of Welfare Debate." American Sociological Review 70:260-87.

$\rightarrow$ Soss, Joe, Richard C. Fording, and Sanford F. Schram. 2008. "The Color of Devolution: Race, Federalism, and the Politics of Social Control." American Journal of Political Science 52:536-53.

- In press. "The Organization of Discipline: From Performance Management to Perversity and Punishment." Journal of Public Administration Research and Theory.

$\rightarrow$ Soss, Joe, Sanford F. Schram, Thomas Vartanian, and Erin O'Brien. 2001. "Setting the Terms of Relief: Explaining State Policy Choices in the Devolution Revolution." American Journal of Political Science 45:378-95.

Soule, Sarah A., and Yvonne Zylan. 1997. "Runaway Train? The Diffusion of StateLevel Reform in ADC/AFDC Eligibility Requirements, 1950-1967.” American Journal of Sociology 103:733-62.

Starobin, Paul. 1998. "The Daddy State." National Journal 30:678-83.

Strolovitch, Dara Z. 2007. Affirmative Advocacy: Race, Class, and Gender in Interest Group Politics. Chicago: University of Chicago Press.

Trattner, Walter I. 1999. From Poor Law to Welfare State: A History of Social Welfare in America. 6th ed. New York: Simon \& Shuster.

$\rightarrow$ Valentino, Nicholas A., Vincent Hutchings, and Ismail K. White. 2002. "Cues That Matter: How Political Ads Prime Racial Attitudes during Campaigns." American Political Science Review 96:75-90.

2009. Punishing the Poor: The Neoliberal Government of Social Insecurity. Durham, N.C.: Duke University Press.

Westra, Karen, and John Routely. 2000. "Arizona Cash Assistance Exit Study, First Quarter 1998 Cohort.” Report. Arizona Department of Economic Security, Phoenix. 
Wu, Chi-Fang, Maria Cancian, Daniel R. Meyer, and Geoffrey Wallace. 2006. "How Do Welfare Sanctions Work?" Social Work Research 30:33-51.

Zimring, Franklin E. 2003. The Contradictions of American Capital Punishment. New York: Oxford University Press. 